\title{
STUDIES OF TWO-PHASE PLUMES IN STRATIFIED ENVIRONMENTS
}

\author{
Massachusetts Institute of Technology \\ Scott A. Socolofsky, Brian C. Crounse and E. Eric Adams
}

February 24, 1999

\section{Contents}

$\begin{array}{lr}\text { Executive summary } & 4\end{array}$

1 Introduction $\quad 6$

2 Purpose of project $\quad 8$

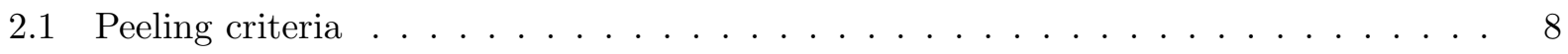

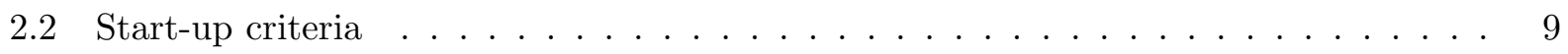

2.3 Effect of droplet characteristics $\ldots \ldots \ldots \ldots \ldots \ldots$

3 Background literature $\quad 10$

4 Experimental setup $\quad 15$

4.1 Glass-walled experimental tank . . . . . . . . . . . . . . . . . 15

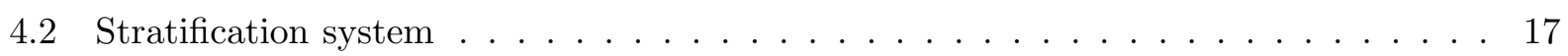

4.3 Density profiles $\ldots \ldots \ldots \ldots \ldots \ldots \ldots \ldots$

4.4 Visualization techniques . . . . . . . . . . . . . . . . . . 19

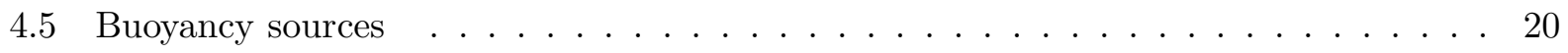

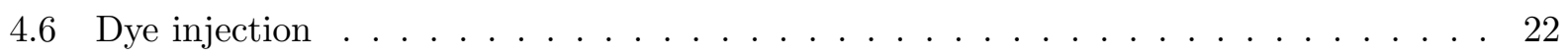

4.7 System Integration using LabviEw . . . . . . . . . . . . . . . . 22

5 Experiments 23

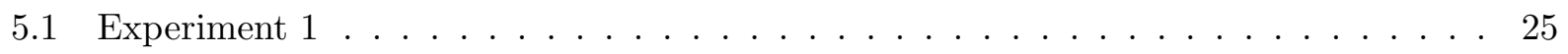

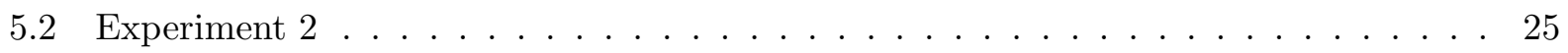




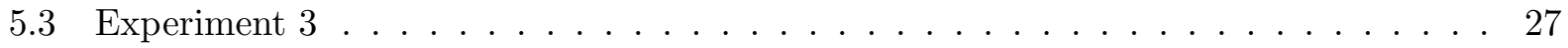

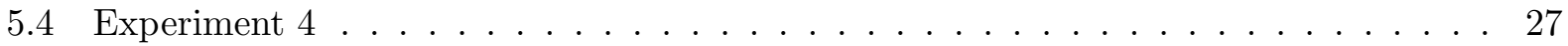

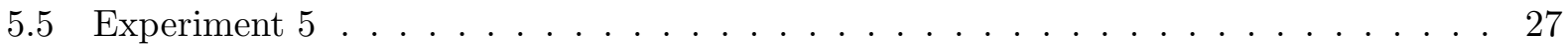

6 Experimental Analysis $\quad 28$

7 Numerical Analysis $\quad 34$

7.1 Governing Equations . . . . . . . . . . . . . . . . . 35

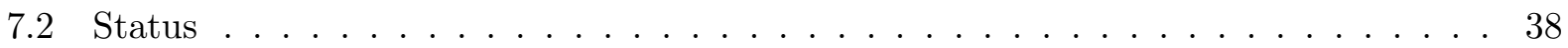

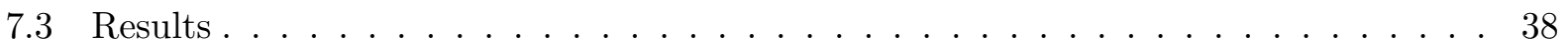

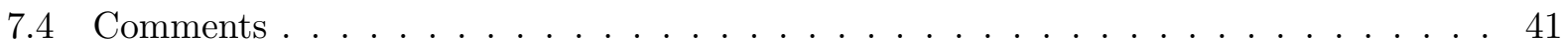

8 Conclusions $\quad 42$

$\begin{array}{lc}\text { References } & 48\end{array}$ 


\section{List of Tables}

1 Characteristics of completed experiments. . . . . . . . . . . . 25

2 Peeling thresholds for passive bubbles. . . . . . . . . . . . . . . 34

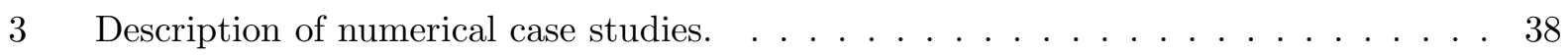

4 Plume rise heights for Cases $1-3 \ldots \ldots \ldots \ldots$. . . . . . . . . . 41

\section{List of Figures}

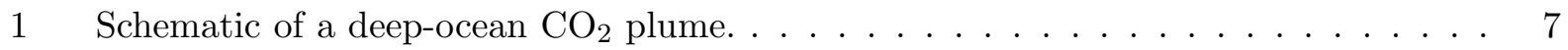

2 Schematic of plume classification. . . . . . . . . . . . . . . . . 13

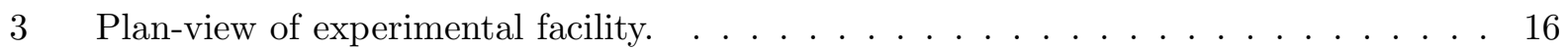

4 Salinity profile in large experimental tank. . . . . . . . . . . . . . . . . 18

$5 \quad$ Asaeda and Imberger (1993) parameter space. . . . . . . . . . . . . . . . . . . . 24

6 Images captured during Experiments 1-4 . . . . . . . . . . . . . . . 26

7 Reingold (1994) sediment data . . . . . . . . . . . . . . . . . 32

8 Modified Asaeda and Imberger (1993) parameter space. . . . . . . . . . . . 33

9 Computer model $\mathrm{CO}_{2}$ plume profiles. . . . . . . . . . . . . . . . 39

10 Computer model $\mathrm{CO}_{2}$ plume centerline concentrations. . . . . . . . . . . . . . 40 


\section{Executive summary}

Two-phase plumes play an important role in the more practical scenarios for ocean sequestration of $\mathrm{CO}_{2}$-i.e. dispersing $\mathrm{CO}_{2}$ as a buoyant liquid from either a bottom-mounted or ship-towed pipeline. Despite much research on related applications, such as for reservoir destratification using bubble plumes, our understanding of these flows is incomplete, especially concerning the phenomenon of plume peeling in a stratified ambient. To address this deficiency, we have built a laboratory facility in which we can make fundamental measurements of plume behavior. Although we are using air, oil and sediments as our sources of buoyancy (rather than $\mathrm{CO}_{2}$ ), by using models, our results can be directly applied to field scale $\mathrm{CO}_{2}$ releases to help us design better $\mathrm{CO}_{2}$ injection systems, as well as plan and interpret the results of our up-coming international field experiment.

The experimental facility designed to study two-phase plume behavior similar to that of an ocean $\mathrm{CO}_{2}$ release includes the following components:

- $1.22 \times 1.22 \times 2.44 \mathrm{~m}$ tall glass walled tank.

- Tanks and piping for the two-tank stratification method for producing step- and linearlystratified ambient conditions.

- Density profiling system using a conductivity and temperature probe mounted to an automated depth profiler.

- Lighting systems, including a virtual point source light for shadowgraphs and a $6 \mathrm{~W}$ argon-ion LASER for LASER induced fluorescence (LIF) imaging.

- Imaging system, including a digital, progressive scanning CCD camera, computerized framegrabber, and image acquisition and analysis software.

- Buoyancy source diffusers having four different air diffusers, two oil diffusers, and a planned sediment diffuser.

- Dye injection method using a Mariotte bottle and a collar diffuser.

- Systems integration software using the LabviEW graphical programming language and Windows NT.

In comparison with previously reported experiments, this system allows us to extend the parameter range of our experiments to better match $\mathrm{CO}_{2}$ injection scenario field conditions and to make detailed measurements of the experimental plumes. 
To-date we have run a basic suite of experiments covering a range of injected fluids (air and oil), flow rates $(0.004$ to $0.083 \mathrm{l} / \mathrm{s})$, bubble/droplet sizes $(0.05$ to $1.5 \mathrm{~cm})$, bubble slip velocities (5 to $35 \mathrm{~cm} / \mathrm{s}$ ), and ambient stratification types (linear and step). Qualitative observations of plume type (frequency and nature of peeling) from these experiments, as well as other experiments from the literature, have been correlated with dimensionless parameters to help us better characterize plume behavior. At the same time, quantitative data are being compared with a new analytical model which treats the flow as an upward-moving inner plume, coupled with an annular, downwardflowing outer plume which entrains from and intrudes into the ambient seawater. The model also includes $\mathrm{CO}_{2}$ specific features such as bubble/droplet mass transfer, solute dissolution effects on plume buoyancy, and change in total $\mathrm{CO}_{2}$ concentration and $\mathrm{pH}$.

We are continuing to conduct experiments which will provide additional data for model calibration. In turn, the model will be applied to $\mathrm{CO}_{2}$ injection to help us better understand field-scale $\mathrm{CO}_{2}$ releases, including those associated with the up-coming international field experiment. 


\section{Introduction}

Two-phase plumes have historically been studied in a variety of situations, including bubble breakwaters, bubble curtains for contaminant containment, bubble jets for destratification in lakes and prevention of ice formation in harbors, reaeration in lakes and reservoirs, bubble barriers for shockwave protection from underwater explosions, and oil well blow-outs (Asaeda \& Imberger 1993, Jones 1972, McDougall 1978). Recently, two-phase plumes have played a role in proposed deepocean sequestration of carbon dioxide to help mitigate potential global climate change (Liro et al. 1991, and Caulfield 1996). Figure 1 shows a schematic of a deep-ocean $\mathrm{CO}_{2}$ release and identifies key nomenclature. Contrary to deep-ocean plume behavior, most of the existing studies of two-phase plumes focus on highly energetic plumes in weakly stratified and step-stratified shallow waters, which form a single intrusion layer near the peak density gradient of the stratification (Lemckert and Imberger 1993, Baines and Leitch 1992, and Patterson and Imberger 1989). Deep-ocean plumes of $\mathrm{CO}_{2}$ in either a bubble or droplet form would experience a linear ambient stratification and would be designed so that all of the injected $\mathrm{CO}_{2}$ and entrained seawater would trap below the thermocline, having several detrainment events from the injection point to the crest of the plume (Caulfield 1996, Liro et al. 1991). The environmental impacts of such a $\mathrm{CO}_{2}$ plume depend on the detrainment and secondary plume start-up processes which are not fully understood.

In a review of $\mathrm{CO}_{2}$ injection methods, Adams and Herzog (1996) found that bubble and droplet plumes were the most promising disposal methods because they are the simplest and the least costly both in terms of energy and maintenance. Several modeling investigations of $\mathrm{CO}_{2}$ plumes have approached plume design by predicting the distribution of $\mathrm{CO}_{2}$ in the water column and the resulting environmental impacts. An integral model of a $\mathrm{CO}_{2}$ plume for a $500 \mathrm{MW}$ power plant was developed by Liro et al. (1991 and 1992); the model accounted for the dissolution of $\mathrm{CO}_{2}$ from the plume into the water column and the possibility of several peeling events. Caulfield et al. (1997) extended the Liro et al. (1991) model to include the density change of the entrained sea water due to the dissolution of $\mathrm{CO}_{2}$ and predicted the resultant $\mathrm{pH}$ change in the far-field water column. Caufield et al. (1997) also developed a stochastic random-walk model to quantify the time-history $\mathrm{pH}$ experience of a passive organism swept through the plume. Based on dose response data compiled by Auerbach et al. (1997), the model was then used to estimate the organism mortality for various plume designs. Among the important parameters determining the organism mortality flux were the intrusion layer thickness, the number of intrusions, and the intrusion layer flux (Caulfield 1996, Adams et al. 1997). The droplet size and the possible formation of clathrate hydrate scales were also important factors and are under investigation at a number of research 


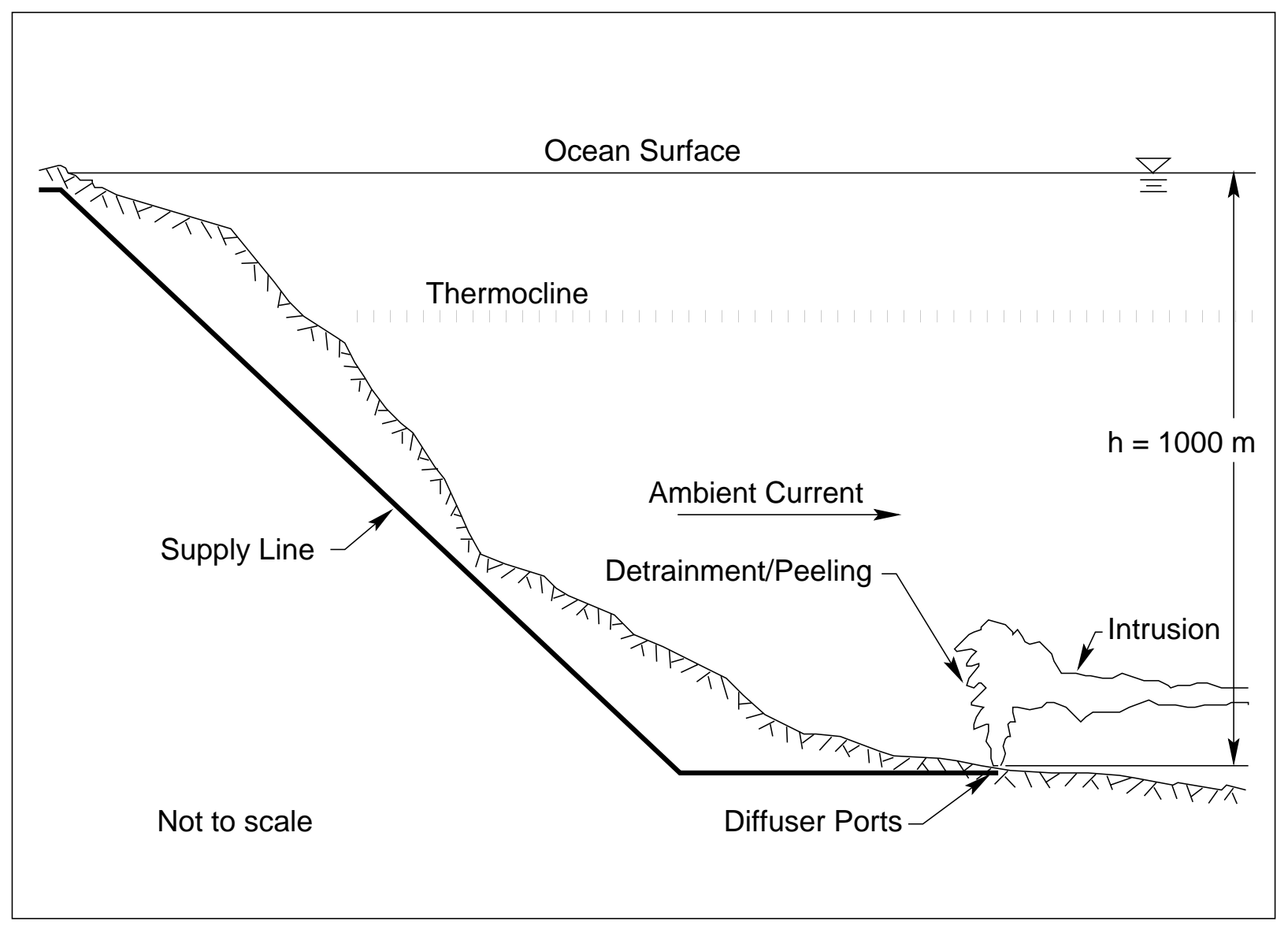

Figure 1: Schematic of a deep-ocean $\mathrm{CO}_{2}$ plume with related nomenclature. 
institutes. Although these models and a similar model by Thorkildsen et al. (1995) predict many peeling events, the models must arbitrarily set parameters controlling the peeling process because of a lack of experimental observations; thus, organism mortality remains uncertain.

Other researchers have used more physically-based models of the peeling process (e.g. Alendal et al. 1998, Asaeda and Imberger 1993, and McDougall 1978); however, the amount of peeled water at each detrainment and the location of detrainment events remains largely arbitrary. The Alendal et al. (1998) model has the highest level of complexity, solving a three-dimensional, eddy-diffusivity model on a fine mesh in the near-field of the plume. However, detrainment is too fine-scale of an event to be modeled explicitely, even in such a complete model. The sensitivity analysis by Caulfield (1996) and Adams et al. (1997) shows that potential organism impacts for $\mathrm{CO}_{2}$ plume injections for a $500 \mathrm{MW}$ power plant could be avoided by a variety of designs if the peeling parameters could be quantified. The efficiency and performance of each design would also depend in large part on a detailed understanding of the plume peeling and intrusion dynamics. Therefore, experimental studies of the peeling process for two-phase plumes in stratified environments have been initiated. This report summarizes our progress over the last two years.

\section{Purpose of project}

Although considerable effort has been placed on modeling of two-phase plumes in stratified environments, the characteristics of multiple peeling plumes, such as would occur in ocean $\mathrm{CO}_{2}$ sequestration, remain arbitrary. Thus, the laboratory experiments performed under this project are designed to give the most information possible on the peeling and intrusion phenomena and the start-up of new plumes for the purpose of calibrating numerical models of deep ocean $\mathrm{CO}_{2}$ plumes. Through modeling, we are interested in predicting the fate of the $\mathrm{CO}_{2}$ droplets and the extent and mixing of the dissolved $\mathrm{CO}_{2}$ and seawater plume. To accomplish this, three primary questions must be addressed. First, under what conditions does a two-phase plume peel and what determines the amount of fluid that leaves the plume at a peel? Second, what are the start-up conditions (centerline velocity, density defect, and plume width) of subsequent plumes after peeling? Third, what are the significant effects of droplet characteristics such as size, density, and slip velocity on the attributes of the final plume?

\subsection{Peeling criteria}

Asaeda and Imberger (1993) assume that all of the plume fluid peels at each peeling event and that peels occur when the net plume momentum reaches zero. Similarly, McDougall (1978) 
assumes that all of the fluid outside the narrow bubble core (approximately $70 \%$ of the plume fluid) peels at the same height as Asaeda and Imberger (1993). By contrast, Liro (1991) and Caulfield (1996) assumed that half of the fluid peels and that peels occur when the net buoyancy flux is zero. Our experiments confirm that there are special cases where all of the fluid appears to peel; however, in the majority of our experiments, a significant portion of the entrained plume water continues beyond a peeling event. This was shown clearly by the movement of dye from the base of the plume through at least 10 peeling episodes for a continuously peeling plume. The peeling volume is important for ocean $\mathrm{CO}_{2}$ plume modeling to be able to predict the ultimate rise height and the amount of dilution. By varying bubble size, buoyancy source density, stratification, and initial buoyancy flux, our experiments can be used to determine the functional dependence of the amount of peeling fluid on each of these parameters.

\subsection{Start-up criteria}

Each of the models discussed so far assumes that the plumes forming above a peeling zone restart with widths and velocities specified only by continuity and accounting for the amount of fluid that peels. Actual experiments, however, indicate that the subsequent plumes do not neck down as much at a peeling zone as that assumption would imply (McDougall 1978). The ejecting fluid can widen the plume bubble core (and in the limit of very small bubbles, this can be a dramatic effect), and the amount of fluid detrained will depend on several characteristics of a given plume, including buoyancy flux, bubble size, and slip velocity. The secondary start-up conditions used in models affect where the plume fluid intrudes and the extent of mixing in the plume; hence, start-up criteria are as important as peeling criteria in determining the near and far-field effects of the $\mathrm{CO}_{2}$ plume. Direct visualization techniques coupled with density and injected dye concentration profiles permit quantification of the secondary plume startup conditions. These are investigated using a range of diffuser and droplet types.

\subsection{Effect of droplet characteristics}

As our experiments have already confirmed, when bubbles are small enough, they lack the strength to adhere to the inner plume core and tend to move with the fluid, leaving the plume at a peeling zone, and then reforming a diffuse plume above the peel. Hence, if the bubbles peel with the fluid, subsequent plumes will have very different start-up conditions than plumes that have a tight, unaltered droplet core. Additionally, peeling bubbles may be carried into the intrusion layer. To predict the ultimate fate of $\mathrm{CO}_{2}$ droplets in an ocean plume, it is important to know when 
and how the bubbles might peel. The slip velocity of the bubbles should be a determining factor for whether bubbles peel or remain in the plume core. This depends not only on size, but also on droplet density. Our wide range in buoyancy sources, flow rates, and stratification strengths provide the flexibility to calibrate a bubble peeling threshold and the dependence of key parameters (entrainment and percent fluid peeled) on bubble characteristics.

\section{Background literature}

Before presenting the results of the experiments and numerical studies, a thorough background review is given, outlining the areas of strength and weakness in our historic understanding of two-phase plumes and their application to ocean $\mathrm{CO}_{2}$ sequestration.

Numerical plume models began out of an interest in forced, convective, single-phase plumes in the atmosphere, first summarized in the classic paper by Morton, Taylor, and Turner (1956). Morton et al. (1956) demonstrated the flexibility of the entrainment assumption, first identified by Taylor in the 1940's and later popularized in a review lecture by Batchelor (1954), which forms the essential part of the analysis of buoyant, turbulent plumes in stratified environments (Turner 1986). Stated simply, the entrainment assumption predicts that the mean inflow velocity across the edge of a turbulent flow is proportional to a characteristic velocity in the flow at the level of inflow (Turner 1986). The ordinary similarity solutions for a plume in a uniform environment do not apply when there is stratification because, as the plume entrains ambient fluid and changes density, it passes through a level of neutral buoyancy, where the downstream velocity vanishes and the plume is said to trap (Morton et al. 1956, Turner 1986). The entrainment assumption, however, is still assumed to be valid for the stratified case, implying the same kind of turbulence structure and balance of forces, but without relying on similarity solutions of the usual kind (Morton et al. 1956). This approach is robust in stratified environments because the entrainment coefficient enters the governing equations with weak sensitivity (Turner 1986). Morton (1959) also showed that continuous, distributed sources could be approximated by virtual point sources and treated by the analysis of Morton et al. (1956). Using a single entrainment coefficient for pure plumes, these models have successfully been applied to a range of problems, from laboratory scales of fractions of a meter, up to the scales of forest fires and volcanic eruptions, where plumes have reached heights of 40,000 m (Turner 1986).

The first successful analysis of the flow induced by two phase (air-bubbles) plumes was by Kobus (1968) for a uniform ambient environment. In laboratory experiments in a $4.7 \mathrm{~m}$ deep basin, Gaussian profiles were fit to the velocity measurements and were postulated for the density defect 
in the plume. An integral plume model was proposed based on an entrainment assumption, the Gaussian profiles, and taking into account the changing air volume with depth and an experimental effective transport rate of buoyancy due to the velocity difference between the bubbles and the plume fluid (Kobus 1968). Ditmars and Cederwall (1974) extended Kobus' model to include the bubble slip velocity directly. Ditmars and Cederwall (1974) also estimated the entrainment rate as a function of gas flow rate and found it to lie between values for pure jets (0.057) and pure plumes (0.082). Other researchers have found a wider range of values for the entrainment coefficient (Milgram 1983, Kobus 1968, Hugi 1993). Milgram (1983) found a dependence of the entrainment coefficient on the plume center-line gas fraction, the bubble flow rate, and the bubble size. Milgram (1983) reports measured entrainment coefficients between 0.035 and 0.16 . Researchers at the Eidgenossiche Technische Hochschule (ETH) Zürich also report a range of entrainment coefficients from 0.01 to 0.10 (Hugi 1993). The lowest values of entrainment were for a straight-tube diffuser (large, fastmoving bubbles) and for a large (15 cm diameter) porous plate (small, diffuse bubbles), but for airflow rates much lower than for Milgram (1983), Kobus (1968), or Cederwall and Ditmars (1974). Together, the data follow a general trend from low values at low flow rates towards the pure plume value of 0.082 with increasing flow rate; however, other factors were also important (Hugi 1993). In further modeling studies, estimates of the spreading ratio between the density defect and velocity profiles indicated an exact correlation with the turbulent Schmidt number (Ditmars and Cederwall 1974). The Schmidt number, therefore, enters the equations, but is not an independent parameter. Finally, based on experiments in a deep well and a review of the literature, Milgram (1983) added a momentum amplification factor to the integral model developed by Kobus (1968) and Ditmars and Cederwall (1974) to account for the momentum carried in the plume turbulence. Although this coefficient can be as high as 2.8, Liro et al. (1991) showed that there is little sensitivity in the results to constant values of the momentum amplification factor and stated that it is approximately unity for a prototype $\mathrm{CO}_{2}$ plume.

Additional experimental studies of bubble plumes have quantified many characteristics of the two-phase flow using a wide range of techniques (Tacke et al. 1985, Sun and Faeth 1986, Cheung and Epstein 1987, and Castello-Branco and Schwerdtfeger 1996, Hugi 1993). Tacke et al. (1985) developed an electro-resistivity probe to measure gas concentration, bubble frequency, and bubble velocity. Their measurements confirmed the use of Gaussian profiles for the density defect in the plume. Sun and Faeth (1986) measured the turbulent properties of bubble plumes. Bubble size distributions were measured using photographic techniques. Bubble and plume fluid velocities were measured using a modified LASER-Doppler anemometer (LDA) technique. The measurements by Sun and Faeth (1986) showed that bubble slip is important throughout the established plume, 
and that turbulent dispersion is important everywhere in the plume. Both Milgram (1983) and Kobus (1968) used propeller anemometers to measure plume liquid velocities. Castello-Branco and Schwerdtfeger (1996) used particle image velocimetry (PIV) in a scaled-down vessel to investigate recirculation currents for an eccentric plume. Hugi (1993) used PIV techniques with a moving bubble source to measure the trailing vorticies of a bubble plume in a uniform cross-flow .

These experimental studies have been limited by the inability to control bubble size and by the physical size of experimental basins. Kobus (1968) was the first to report that bubble size was purely dependent on gas flow rate, independent of the orifice diameter for a straight-tube diffuser. Matsunashi and Miyanaga (1990) confirmed this finding for the field-scale plume. McDougall (1978) created smaller bubbles by adding octanoic acid (30 ppm) to his laboratory tank. Reingold (1994) proposed a solution for bubble size control whereby sediment was used as the buoyancy source, and the plume was inverted. In trials comparing sediment to bubbles having similar slip velocities and carrying equal buoyancy, sediment was shown to be an acceptable model for air bubbles for predicting plume peeling heights in stratified environments (Reingold 1994). Reingold's (1994) tank (1.0 × $3.0 \times 0.8 \mathrm{~m}$ deep) was not deep enough, however, to investigate several peels. Experimental basins in the literature vary widely in lateral dimension, but most are about $1 \pm 0.3 \mathrm{~m}$ deep. Exceptions include Kobus (1968): $4.7 \mathrm{~m}$ deep, Marco et al. (1996): $2.25 \mathrm{~m}$ deep, and Hugi (1993): $3.0 \mathrm{~m}$ deep, none of whom investigated stratification.

Models of bubble plumes in stratified environments began with the integral and double-plume models of McDougall (1978), designed to predict the distribution of oil in the water column after an oil-well blow-out. The effects of gas expansion and bubble slip velocity for the stratified case were incorporated with the model of Cederwall and Ditmars (1974) as a first attempt to model the problem (McDougall 1978). Bubble plumes differ from single-phase plumes by the bubbles, which rise through the point where the simple plume traps and then are assumed to create an iterated structure of similar plumes above the periodic intrusions. McDougall (1978) does not apply his simple integral model beyond the first peel. Liro et al. (1991), however, did include the peeling process and resulting secondary plume start-up in a simple integral model. Peeling occurs in the Liro et al. (1991) model whenever the negative buoyancy of the water has a greater magnitude than the positive buoyancy of the bubbles. At that point, one-half of the volume flux, one-half of the momentum flux, and three-quarters of the buoyancy flux are arbitrarily ejected from the plume (Liro et al. 1992). The secondary plume resumes after similar adjustments to the plume width and velocity to maintain continuity.

McDougall (1978) modeled peeling in a more complicated model, called a double plume model, where the inner plume contained the bubble core and an outer, ring-shaped plume contained water 


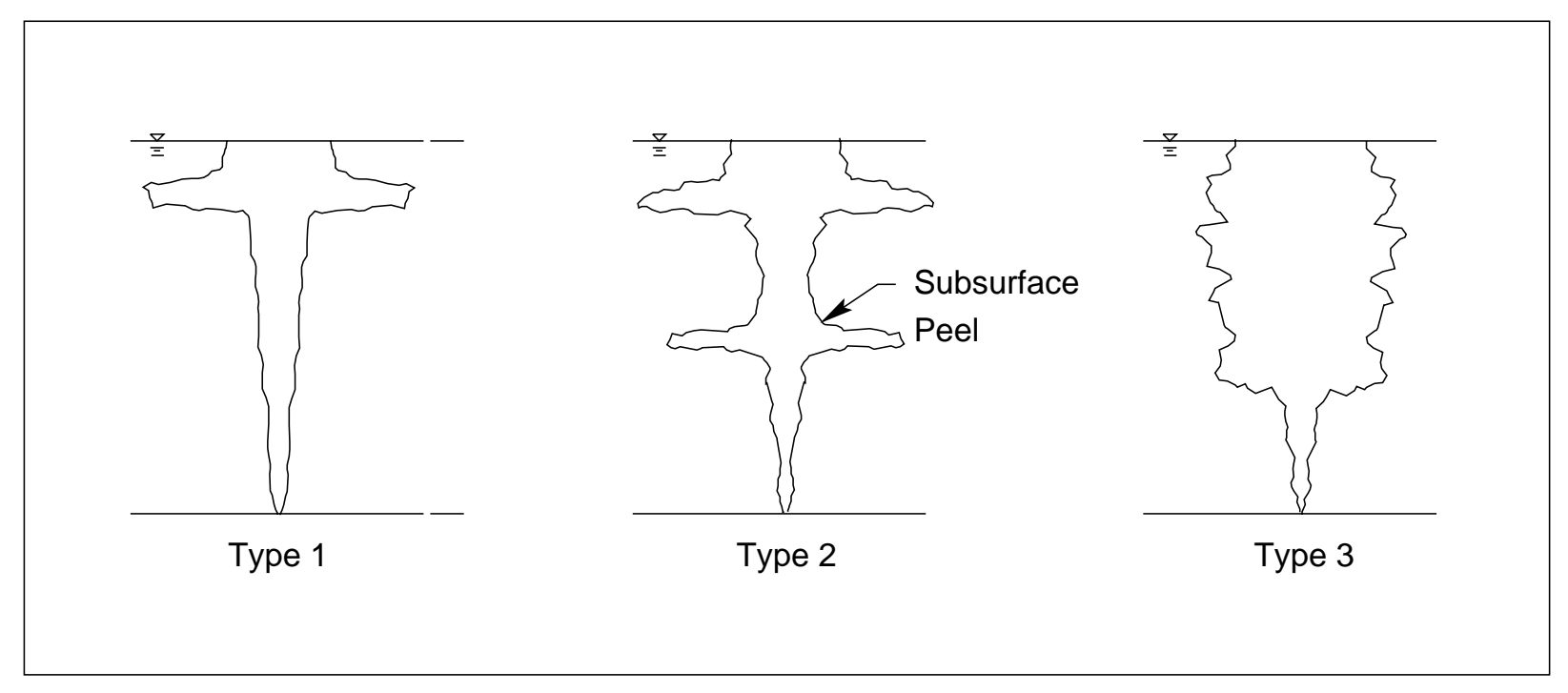

Figure 2: Schematic of plume classification as given in Asaeda and Imberger (1993).

only. This model developed out of experiments he performed in a $0.6 \times 0.6 \times 1.3 \mathrm{~m}$ deep tank. The double-plume model was integrated simultaneously up to a point where the outer plume radius increased rapidly and the velocity became negligible. At that point, the plume was beginning to peel. Several attempts were made to restart the model at a point just above the peeling zone, where the upward and downward fluxes of water in the inner and outer plumes, respectively, were balanced. The only stable solution, however, was to restart the plume just above the point where the downdraught of the peel began. At that level, the inner plume quantities remain unchanged from the previously calculated level, and the outer plume is re-started with zero volume and momentum flux. Experiments did not show quite such a dramatic necking-down of the outer plume as assumed in the model (McDougall 1978). The double-plume model was able to simulate several peeling events, but underestimated the level of the first peel in the experiments by up to $40 \%$. Baines and Leitch (1992) also reported that McDougall's (1978) double-plume analysis underpredicted the height of the first peel for their linearly stratified case.

Baines and Leitch (1989) and Lemckert and Imberger (1993) performed additional experiments in linear and step-stratified environments, confirming the qualitative findings of McDougall (1978). Asaeda and Imberger (1993) used a 1.0 x 1.0 x 0.75 m deep tank with linear stratification and variable bubble source strengths, and their observations led them to develop a hybrid double-plume model. They identified three distinct flow regimes (labeled Types 1, 2, and 3, shown qualitatively in Figure 2) and classified each flow using two non-dimensional numbers: $M_{H}$ and $P_{N}$. $M_{H}$ represents the bubble source strength compared to the total pressure head, and $P_{N}$ represents the effect of 
the stratification compared to the bubble source strength. Type 1 plumes are vigorous enough that they carry all of their entrained water to the surface, forming one intrusion layer. At a critical value of $P_{N}$, Type 2 and 3 plumes appear. For low $M_{H}$ (Type 3 ), the plume appears to continuously peel, forming dozens of randomly-spaced, finger-like peels throughout the length of the plume. Type 2 plumes occur for higher values of $M_{H}$, forming several distinct peels, each remaining independent from the rest. Shadowgraph visualization of the Type 2 plumes showed that an outer plume forms a downward flowing ring from the flow separation down to the level where the intrusion layer forms. In the model proposed by Asaeda and Imberger (1993) a simple integral plume model is integrated from the source to the point where the upward momentum is zero. At that level a second, outer plume model, is started, such that the upward flux of the inner plume is balanced by the downward flux of the outer plume (i.e 100\% of the plume fluid peels). McDougall (1978) showed that the two plume fluxes should actually balance below this point. The outer plume entrains fluid from the inner plume and the ambient water as it descends until it reaches a level of neutral buoyancy where it is allowed to intrude. The secondary plume starts up again with zero volume flux, the buoyancy of the bubbles, and the width of the inner plume at the level where the outer plume began. This method predicted multiple peeling events better than McDougall's (1978) model, but remains arbitrary in setting the initial flux in the downdraught plume and in the start-up conditions of subsequent plumes.

While models are still developing, applications of bubble plumes in stratified environments have been made extensively for lake and reservoir management, both to enhance vertical mixing and to provide reaeration to the hypolimnion (Goossens 1979, Patterson and Imberger 1989, Wüest et al. 1992, and Schladow 1993). Measurements of the surface intrusion, including the radial extent to the plunge line, the volume flow rate, and the level of the intrusion in the far field, have been reported by several researchers for field and laboratory experiments and scale with the stratification and bubble source characteristics (Lemckert and Imberger 1993, Goossens 1979, Zic et al. 1992, Schladow 1993, Baines and Leitch 1992, Leitch and Baines 1989).

To assess the far-field effects of bubble plumes for reservoir management, models have been developed coupling simple integral models to various dynamic reservoir models (Goossens 1979, Patterson and Imberger 1989, and Wüest et al. 1992). Patterson and Imberger (1989) developed a coupled model, using the simple integral model of McDougall (1978) and the one-dimensional dynamic reservoir model DYRESM. They discretized the plume at the same levels as the layers in DYRESM and simulated the entrainment and transport of water between layers. When the vertical velocity becomes zero, the plume is ejected horizontally (mixing across the layer instantaneously) and is restarted at the next layer. They were able to predict the new turn-over time for a reservoir 
that was mixed by a bubble plume and used the model to enhance the plume system design. Wüest et al. (1992) developed a simple integral plume model, similar to Patterson and Imberger (1989), to study both reaeration and reservoir mixing. The model included gas transfer between the bubbles, calculated the concentrations of gases in the air and water, and tracked the water quality changes in the reservoir due to the presence of the plume. As the basis for a design methodology for reservoir mixing bubble plumes, Schladow (1993a, 1993b, and 1991) proposed using two important nondimensional parameters: $M$ and $C$ (Modified versions of $M_{H}$ and $P_{N}$ ). His design methodology was validated in a coupled plume-reservoir model similar to Patterson and Imberger (1989). Although simple integral models involving gas-transfer, buoyancy transfer between layers, and intermediate plume peeling have been developed in these reservoir studies, detailed analysis of the peeling and intermediate intrusion dynamics have not been necessary because most of the plumes are of Type 1 , having no intermediate peels. In the case of step stratification, peeling can occur at the thermocline and the surface (a form of a Type 2 plume), but the steep density gradient reduces uncertainty in the location of the peel and the level at which the intrusion layer will form (Lemckert and Imberger 1993).

\section{Experimental setup}

To investigate the issues outlined in the previous sections, a comprehensive experimental setup has been built. Figure 3 shows a plan-view of the laboratory setup, including the glass-walled experimental tank and associated structures. The integrated set-up should be viewed as a number of sub-systems. These systems include the experimental tank, the stratification system, visualization techniques, density profiling, buoyancy source injection and measurement, and data collection and analysis.

\subsection{Glass-walled experimental tank}

The first, and most fundamental, component of the experimental setup is the glass-walled experimental tank. Several requirements were placed on the tank design. For visualization and interrogation purposes, there needed to be at least three, full-sized walls of unobstructed, clear glass. The tank also had to be deep enough that multiple sub-surface peels could be produced using an economical stratification profile. Asaeda and Imberger (1993) give a relationship for the number of sub-surface peels, $n$, as

$$
n=0.22 P_{N}^{\frac{1}{4}}
$$




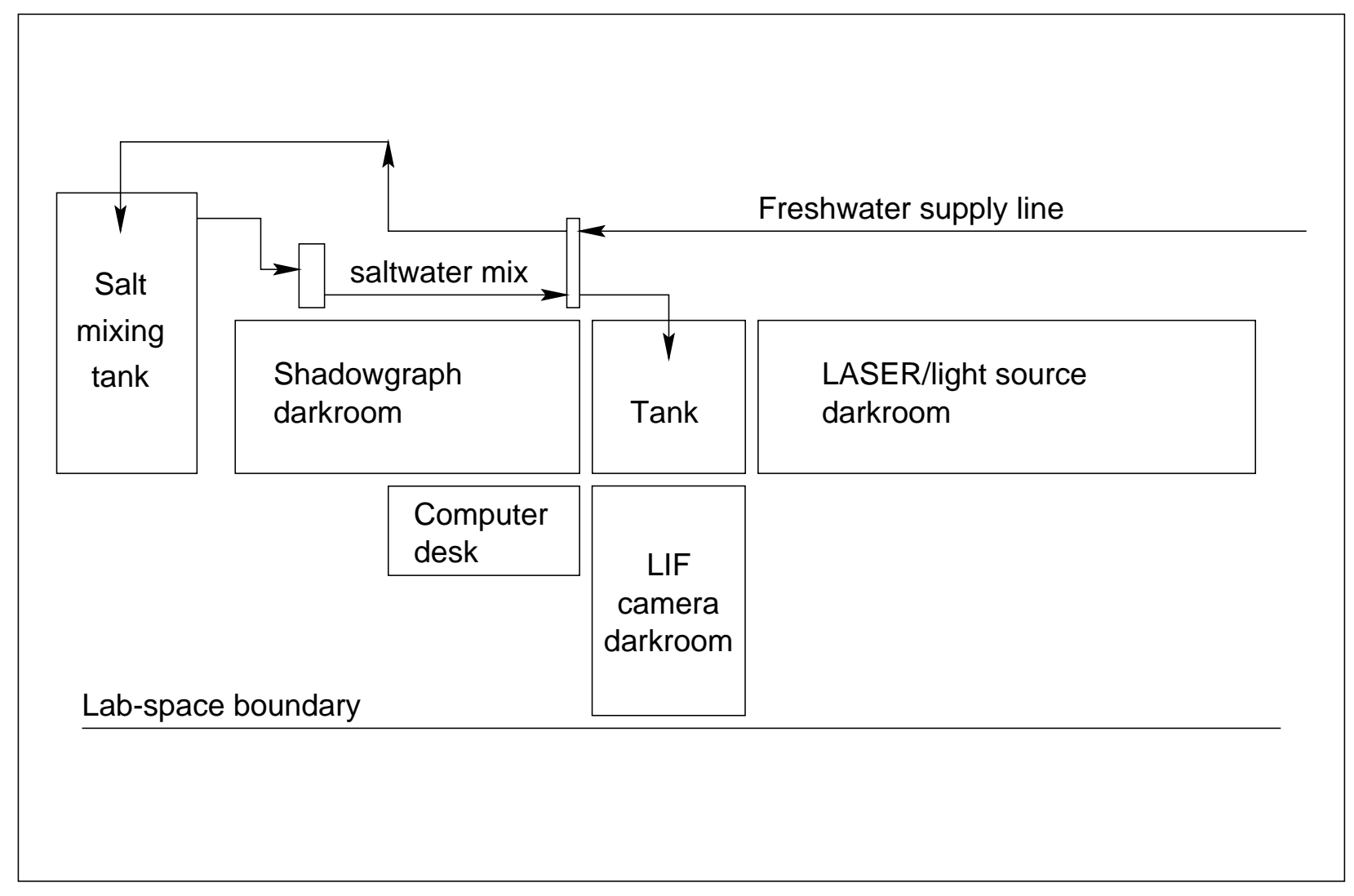

Figure 3: Plan-view of experimental facility showing the glass tank, visualization darkrooms, salt mixing tank, and computer housing. 
where $P_{N}=N^{3} H^{4} /\left(Q_{B} g\right)$ and $N=\sqrt{-g / \rho(d \rho / d z)}$ is the buoyancy frequency, $g$ is the gravitational constant, $\rho$ is the reference liquid density, $z$ is the vertical ordinate taken positive upward from the diffuser orifice, $H$ is the total pressure head at $z=0$, and $Q_{B}$ is the bubble flow rate at $z=0$. If the tank is stratified with salt from $30 \mathrm{ppt}$ at the bottom to fresh water at the top and there are to be three sub-surface intrusions, then $Q_{B} \leq 4.3 \times 10^{-6} \mathrm{~m}^{3} / \mathrm{s}$ for a nominal tank height of $H=2.44 \mathrm{~m}$ $(8 \mathrm{ft})$. This is a modest flow rate, hence a tank of $2.44 \mathrm{~m}$ height was selected.

A request for bids was prepared and was sent to several manufacturers of aquariums, laboratory tanks, and glass construction companies. The lowest bid was for a two-ply (each ply having a thickness of $19 \mathrm{~mm}$ ), tempered glass tank housed in a steel frame and supported by a rectangular metal based. The bid was accepted, and the tank was constructed on site over a three-day period in June 1997.

\subsection{Stratification system}

The tank is stratified using the two-tank method (see e.g. Asaeda and Imberger, 1993). In this method, a salt-water tank with initial concentration equal to the desired bottom concentration in the profile is prepared. Fresh water is pumped into the salt tank through a diffuser, and the mixed water is pumped directly into the experimental tank, dissipating the energy over a splash-plate. If the salt tank is analyzed as a well-mixed reservoir of concentration $C(t)$ with initial volume $V_{0}$, and the flow rates into and out of the tank are constant at $Q_{1}$ and $Q_{2}$, respectively, then the variation of $C(t)$ is given by

$$
C(t)=\frac{C_{0}}{V_{0}}\left(V_{0}-\left(Q_{1}-Q_{2}\right)\right)^{\frac{-Q_{1}}{Q_{1}-Q_{2}}}
$$

where $C_{0}$ is the initial concentration in the tank. For a linear salt profile, the exponent must equal +1 , giving $Q_{2}=2 Q_{1}$. The city water provides a roughly constant flow rate which is piped through a rotometer and directly into the diffuser in the salt mixing tank at a rate up to $35 \mathrm{gpm}$. The outflow from the salt tank is pumped by a $1 \mathrm{hp}$ centrifugal pump, through a second rotometer, and up to the top of the tank. Figure 3 shows a schematic of this scheme. The pump can reach a flow rate of up to $20 \mathrm{gpm}$, allowing the tank to be stratified in less than 45 minutes. Figure 4 shows a profile prepared using fresh and salt water flow rates of 12 and 24 gpm, respectively.

\subsection{Density profiles}

A density profiler is used to measure the initial and evolving density profiles in the tank. To be usable, however, the density profiler must be small enough not to cause measurable mixing while taking the profile and have an automated depth measurement so that profiles can be taken 


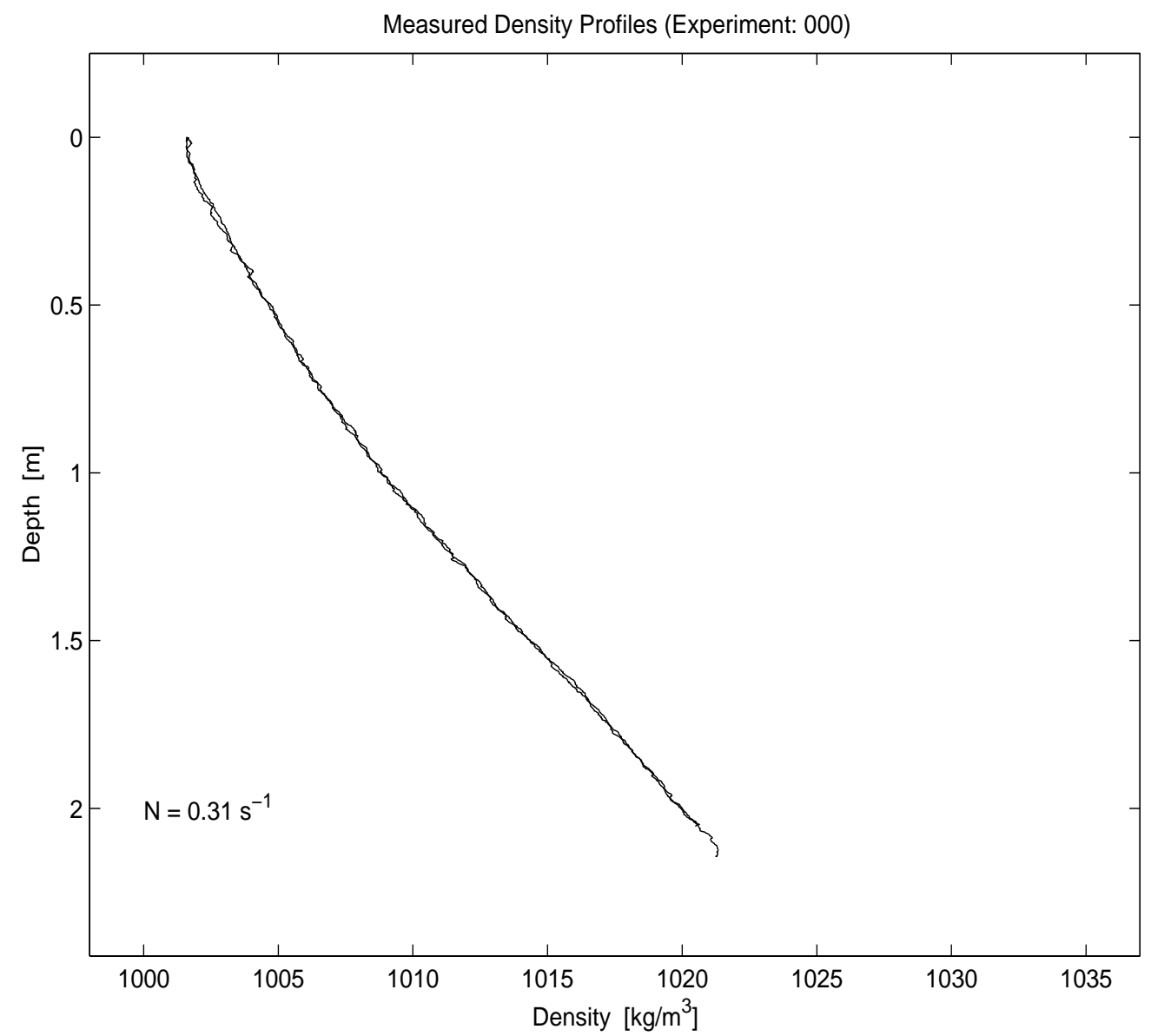

Figure 4: Two salinity profiles for the initial tank stratification. The two profiles were taken separated by a five second pause. 
during or in rapid succession after an experiment. Standard ocean and laboratory conductivity, temperature, and depth (CTD) profilers do not meet these specifications; hence, a custom system was required.

A rapid-response CT probe available from Precision Measurement Engineering (PME) has been used by a number of researchers (e.g. Asaeda and Imberger 1993, Lemckert and Imberger 1993). This probe is $6.4 \mathrm{~mm}$ in diameter and is fixed to the end of a metal tube of the same cross-section. A custom probe with a shaft length of 2.7 meters was constructed by PME for our application. To automate the depth measurement, a Parker, computer-controlled linear actuator (LA) was acquired from Empire Automation. (A LA has a small, belt-driven carriage mounted on a long track that allows accurate positioning of the carriage along the track length.) The Parker LA has a travel length of more than $2.5 \mathrm{~m}$ and allows for complete automation of the carriage movement. The CT probe shaft was mounted on the LA carriage, and the LA was mounted in a corner on the top of the tank. Figure 4 shows two profiles taken by this system; the second profile was taken five seconds after the first, and each profile required about 2 seconds. Minimal mixing and disturbance is observed; hence, rapid density profiles can be made and stored directly to the hard-disk using this system.

\subsection{Visualization techniques}

Two visualization techniques are used in the experiments. Shadowgraphy provides visualization of the integrated plume, and LASER induced fluorescence (LIF) illuminates a single slice through the plume.

To eliminate ambient light from interfering with the visualization, darkrooms were constructed adjacent to the tank. Figure 3 shows a floor plan of the experimental facility. On the far side of the tank, black paper and plastic were applied to the glass to block out the light. On another wall, a $6.1 \mathrm{~m} \times 1.2 \mathrm{~m} \times 2.4 \mathrm{~m}$ tall darkroom was constructed to accommodate both the LASER light source and the shadowgraph light. Directly opposite this room, another room $4.9 \mathrm{~m} \mathrm{x} 1.2 \mathrm{~m} \times 2.4 \mathrm{~m}$ tall was constructed. This room shelters the camera when performing a shadowgraph experiment. The translucent shadowgraph screen is attached to the outside of the glass wall of the tank. In the remaining space, a third darkroom was constructed adjacent to the remaining open glass wall that was $3.0 \mathrm{~m} \times 1.2 \mathrm{~m} \times 2.4 \mathrm{~m}$ tall to house the camera during LIF experiments.

For the shadowgraph visualization, either parallel light rays or a point source of light is shone through the tank and the refracted areas of light and dark are focused on a translucent screen on the opposite side of the tank. Parallel light rays are only possible using collimating optics that have a diameter equal to the desired illumination area. Hence, for our tank, a collimating lens of 
diameter $\geq 2 \mathrm{~m}$ would be required. Since such a lens is prohibitively expensive, a virtual point source of light was created. To do this a tungsten-halogen lamp with a filament size of $18 \mathrm{~mm}$ was positioned on a light rail with two additional optics. First, a $50 \mathrm{~mm}$ diameter collimating lens having a focal length of $200 \mathrm{~mm}$ was placed in front of the light to produce a collimated beam that could be focused down to a point. Second, a $50 \mathrm{~mm}$ diameter doublet lens with a focal length of $140 \mathrm{~mm}$ focused the light down to a point approximately $8 \mathrm{~mm}$ in diameter. A fixed, $10 \mathrm{~mm}$ diameter aperture is placed at the focal point of the doublet lens, allowing a Gaussian beam of light to pass through with a spreading angle of 20 degrees.

For the LIF technique, a LASER light sheet is used to illuminate a cross-section of the plume. The beam from a $6 \mathrm{~W}$ argon-ion LASER is conducted from the LASER housing to the darkroom area via a multi-mode, fiber-optic cable. The fiber-optic cable terminates at a cylinderical lens which spreads the beam out in one direction with a 38 degree spreading angle while leaving the beam in the plane perpendicular to the sheet unchanged. The light sheet is oriented to shine into the tank, illuminating a continuous, vertical slice of the bubble plume. Without using dye, the LASER reflects off the bubbles, illuminating them clearly. By injecting fluorescent dye to mark the plume, the LASER light sheet excites the dye, making the dyed fluid stand out against the dark background. An advantage of the LIF technique is that the brightness of the fluorescing dye is linearly proportional to the concentration of the dye in the water. Hence, by imaging the illuminated plume with a camera, the intensity of light at each pixel can be converted to a dye concentration, giving a measurement of the amount of dilution from the injection point to the point of interest. This technique is described in detail in Papanicolaou (1988).

\subsection{Buoyancy sources}

Most experiments in the literature are for air bubble plumes. We have constructed an air diffuser array, as well as methods for introduction of oil droplets and sediment grains. In the case of oil droplets, a much lower density difference between the droplets and the ambient water is produced, which gives rise to a lower slip velocity and larger mass then for bubbles of the same size. This extends the parameter range of our experiments. Additionally, oil droplets are a better model of liquid $\mathrm{CO}_{2}$ droplets than are air bubbles. Sediment is used to control bubble size (Reingold 1994). Since sediment is negatively buoyant, the particles are introduced at the top of the tank, creating an inverted plume.

In the literature the observation has been made that bubble size is dependent only on flow rate of air and independent of the diffuser orifice diameter (Kobus 1968). In fresh water, bubble size is also nearly independent of the diffuser design altogether. In salt water, however, the lower surface 
tension and increased ionic strength give rise to much smaller bubbles than in fresh water, which leads to a wider range of bubble sizes for a given diffuser design. Jens Beyersdorf (1997) presents data on bubble columns in uniform saltwater solutions. Above a concentration of $8 \mathrm{ppt}$, there is a significant difference between the salt water and fresh water bubbles (Beyersdorf 1997). Our air diffuser array currently consists of four diffusers. One is a simple $3 \mathrm{~mm}$ diameter, straight-tube orifice. A second is a $0.7 \mathrm{~mm}$ diameter orifice air-brush nozzle. It has a tapered design producing a high exit velocity which promotes bubble shattering at the nozzle and yields smaller bubbles. The two remaining diffusers are both designed for aquariums. The first is a green air-stone. Air is forced by compression through the irregular pores in the stone. As the air exits, it nucleates on the small pores creating small bubbles. Due to its shape, the bubbles that form on the sides of the stone tend to aggregate; thus, larger bubbles are found in a ring around the sides of the plume. The bubbles forming on the top of the air-stone do not aggregate, yielding a bubble core of smaller bubbles. The second aquarium diffuser is a limewood diffuser. The porous limewood is cut so that its pores lie perpendicular to the air supply hose. A hole is bored through the center of the diffuser, allowing the source air to fill the diffuser and pressurize the pores in the wood. The air creeps out of the fine pores on the sides of the diffuser. Because the bubbles are much smaller than those formed on the green airstone, they do not aggregate on the sides; hence, the limewood diffuser creates a uniform bubble size distribution of very small bubbles. Approximate bubble diameters for each of the diffusers in sea water with an airflow rate of 1 standard liter per minute are $1 \mathrm{~cm}$ for the straight tube, $0.5 \mathrm{~cm}$ for the airbrush, 0.7 and $0.2 \mathrm{~cm}$ for the large and small bubbles of the green airstone, and $0.01 \mathrm{~cm}$ for the limewood diffuser.

Two diffusers have been assembled for injecting oil. At high flow rates, a $6 \mathrm{~mm}$ inner diameter spray nozzle is used, and at low flow rates, a $3 \mathrm{~mm}$ inner diameter spray nozzle is used. The two nozzles are both designed to create water jets having a 90 degree angle of growth. Using these nozzles with oil at the low flows produced to-date has not produced droplet shattering at the outlet; thus single bubbles form in a uniform size distribution: $2 \mathrm{~cm}$ droplets for the large nozzle and 1 to $1.5 \mathrm{~cm}$ droplets for the small nozzle. Two Cole Parmer positive displacement pumps are used to inject oil over a range of flow rates.

Sediment has been injected in the previous experiments at MIT by Reingold (1994) through an inverted gallon milk jug. Filling the jug with sediment and cutting a few small holes to prevent vacuum formation during injection were shown to produce a uniform flow rate within about $10 \%$ error over the span of an experiment. An alternate injection method has been designed which injects sediment from a motor-driven conveyer belt, insuring a constant, continuous injection rate.

To measure the flow rates of the various buoyancy sources several different techniques are used. 
For air, an electronic mass flow meter was installed in the gas supply line. This meter works by injecting a small amount of heat upstream of a sensor and measuring the heat flux downstream. Once factory calibrated, the device can measure the mass flux of air moving by the sensor (reported as a volume flow rate of air at standard temperature and pressure in std l/min). For oil, each crank of the peristaltic pump motor yields a known quantity of injected liquid; hence, flow rate is calculated from the motor revolutions per minute $(\mathrm{rpm})$. Finally, sediment injection rate is measured by noting the amount of sediment injected and the duration of the experiment.

\subsection{Dye injection}

As already mentioned, for the LIF experiments the plume must be marked by fluorescent dye as a tracer. For this purpose a $1 \mathrm{l}$ bottle of concentrated dye is set up in the Mariotte bottle technique (Fischer et al. 1979). Using this technique a constant flow rate of dye over time is achieved. Dye is piped to the diffuser port through a $6 \mathrm{~mm}$ inner diameter tygon tube and injected about $5 \mathrm{~mm}$ below the diffuser orifice through a circular collar diffuser with a diameter of $40 \mathrm{~mm}$. The dye is made slightly buoyant so that it is easily entrained by the bubble plume and mixed across the cross-section. Dye injection rates must be measured by noting the amount of dye that leaves the Marriot bottle and the duration of the experiment. More precise measurement could be made using a Cole Parmer micro-pump if it becomes necessary.

\subsection{System Integration using LabVIEW}

LabviEw is a flexible data acquisition and systems integration and control programming language. Using the Labview environment, Windows programs can be easily created to acquire data from the many systems and to control linear positioner. Several system programs have been created.

For the visualization, a frame grabbing program has been written to acquire camera data. A Pulnix TM 9701 charged couple device (CCD) camera is used with a 12.5-70 mm focal length zoom lens with f-stops f1.2-f16. The camera can output in analogue mode over a BNC connection or in digital mode through a Pulnix-specialized "airborne" connection. In either mode (digital is the preferred mode) the LabVIEW program first acquires images from the camera and stores them in active memory. When a sequence has been captured, the images are then written directly to the hard disk. The sequencing software has been programmed to take images at an arbitrary time spacing (for instance 10 frames at $30 \mathrm{~Hz}$, followed by 10 frames at $15 \mathrm{~Hz}$, and 120 frames at $0.1 \mathrm{~Hz}$, etc.). With our available computer RAM, up to 600 images can be captured before writing them to the hard disk. The bus speed between RAM memory and the hard drive is not fast enough to 
save the images as they are captured. Triggering of the image acquisition is provided in three ways. First, a simple mouse click can start the acquisition. Second, for remote triggering, a switch was connected to a National Instruments LabPC1200 analogue to digital (A/D) converter card and can be used to initiate data collection. Third, the mass flow meters have output voltages that have been connected to the A/D card so that acquisition can begin when the airflow rate reaches a critical value.

For the density profiles, a program has been written to control the Parker positioner and acquire the data. Labview communicates with the Parker positioner over the COM1 port of the computer using the Parker ASCII command language. This serial communication tells the positioner where to go and how fast to move, then relays back to the computer the real-time position of the carriage. The conductivity and temperature voltages from the PME CT probe are acquired through the A/D card. The program automatically converts to depth and density and saves the raw and computed data to the hard drive. Since the PME CT probe requires calibration for each experiment, a second program was written to record the calibration data and store the calibration coefficients.

As already mentioned, the mass flow meters output voltages that can be acquired by the LabPC1200 and saved to the hard drive. The air supply system is stable enough, however, that the variation in gas flow rate over an experiment is less than the noise in the measurement system. Hence, flow rate is simply recorded once on an experiment data sheet from the reading on the mass flow meter's LED readout.

Once an experiment has been saved to the hard drive, the images can be viewed through another program that can load in the saved images and display them to the screen like a video player. This program has functions for the variable capture rate, forward, reverse, reset, fast forward, fast reverse, pause, and slow motion. Numerical analysis of the images has been conducted mostly in Matlab by The MathWorks, Inc. and to a lesser extent in Adobe Photoshop.

\section{$5 \quad$ Experiments}

Five major experiments have been completed. In the deep-ocean we would never expect a plume to reach the surface without peeling; thus, Type 1 plumes are irrelevant to this study. However, two Type 2 and two Type 3 plumes were created in linear stratification, each with significantly different parameter values than plumes previously reported by Asaeda and Imberger (1993). A fifth plume was created in step stratification. Figure 5 shows all of the data assembled by Asaeda and Imberger along with points for the four experiments thus far completed in linear stratification. Experiment 1 was the classic Type 2 plume with one sub-surface peel and agreed exactly with 


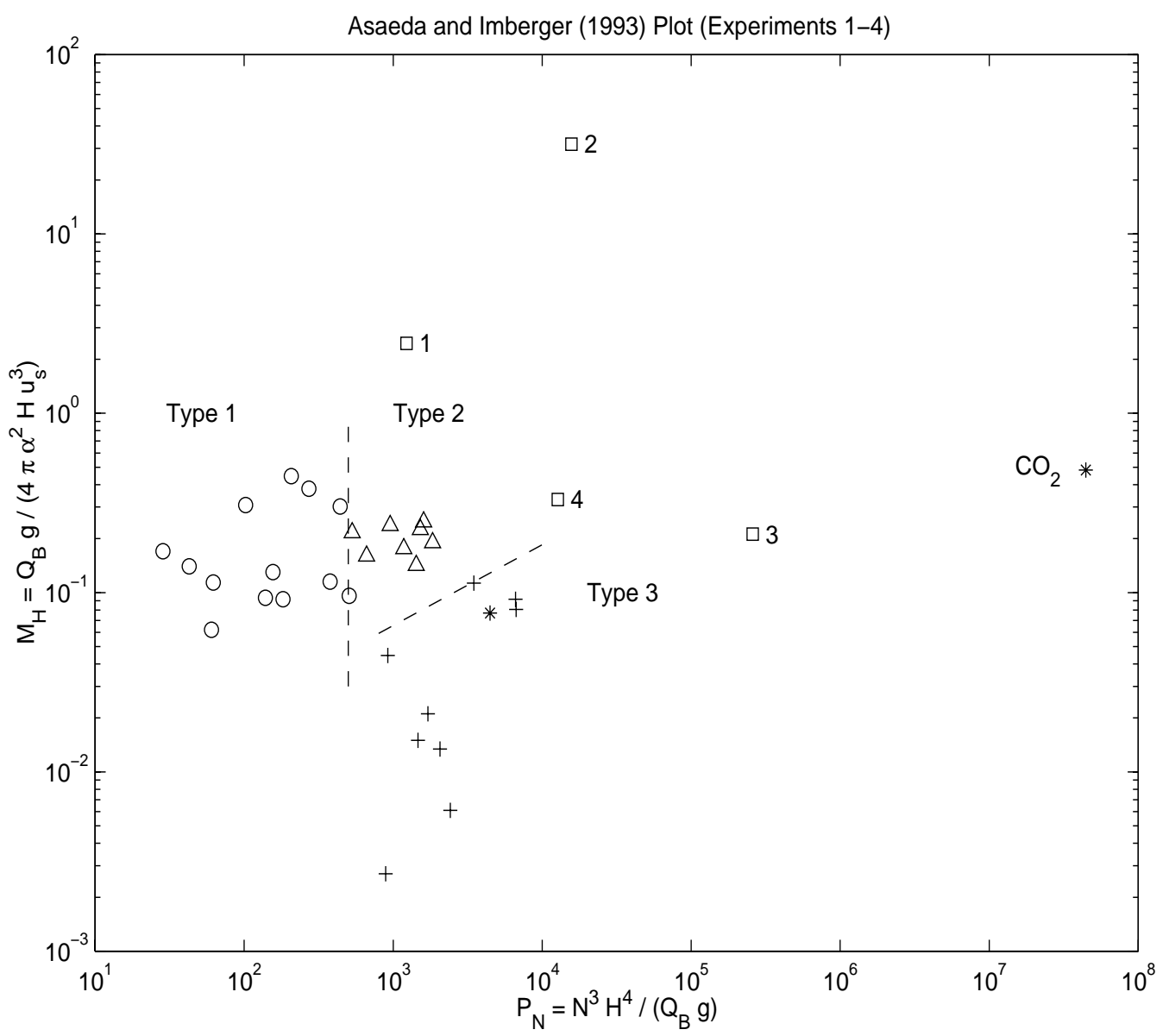

Figure 5: Asaeda and Imberger (1993) parameter space with completed experiments. Circles are Type 1 plumes, triangles are Type 2 plumes, and pluses and stars are Type 3 plumes reported in Asaeda and Imberger (1993). The squares show the data for Experiments 1-4, and the star at the far right shows the plotting point for a typical $\mathrm{CO}_{2}$ injection of $1 \mathrm{~kg} / \mathrm{s}$ at $1000 \mathrm{~m}$ depth. This injection rate corresponds to the anticipated pilot scale field experiment or one out of 100 nozzles from a manifold releasing $\mathrm{CO}_{2}$ from a 500 MWe power plant. 


\begin{tabular}{|c|c|l|l|l|c|}
\hline Experiment & Buoyancy Source & Diffuser & Stratification & $\begin{array}{l}\text { Flow Rate } \\
{[\text { std l/min }]}\end{array}$ & Type \\
\hline 1 & air & airstone & linear & 3.5 & Type 2 \\
\hline 2 & air & limewood & linear & 0.5 & Type 2 \\
\hline 3 & air & airstone & linear & 0.5 & Type 3 \\
\hline 4 & oil & low-flow & linear & 0.25 & Type 3 \\
\hline 5 & air & limewood & step & 0.35 & Type 3 \\
\hline
\end{tabular}

Table 1: Characteristics of completed experiments.

Asaeda and Imberger's (1993) classification. Experiments 3 and 4 were both Type 3 plumes, indicating that the line separating Type 2 and 3 should move up slightly. Experiment 2 was not simply a Type 2 or 3 , but had characteristics similar to both. Experiment 5 was a bubble plume of very small bubbles created with the limewood diffuser in two-step stratification to get a very stable, yet artificial, Type 2 plume with two sub-surface peels. Figure 6 shows an image taken during Experiments 1-4. Table 1 compares the relevant parameter values for each experiment.

\section{$5.1 \quad$ Experiment 1}

The first experiment was a shadowgraph designed to give a single, discrete, sub-surface peel. A moderate bubble flow rate of $3.5 \mathrm{std} \mathrm{l} / \mathrm{min}$ was supplied to the green airstone diffuser in an ambient stratification with a buoyancy frequency of $N=0.29 \mathrm{~s}^{-1}$. Unfortunately, the single peel occurred about $40 \mathrm{~cm}$ from the surface, so that it was at the limit of the camera field of view. By visual observation, however, it appeared that all of the entrained water peeled from the plume and that the location of the peel remained constant until the whole tank volume below the peel point was well mixed. The bubbles appeared unaffected by the peel. This experiment confirmed the observations already reported in the literature.

\subsection{Experiment 2}

This experiment presented the greatest difference between what was expected and what was actually observed. The experiment was recorded with shadowgraphy, and was designed to give four, discrete sub-surface peels. The plume was created with a medium airflow rate of approximately $0.5 \mathrm{std} \mathrm{1/min} \mathrm{(At} \mathrm{the} \mathrm{time} \mathrm{of} \mathrm{this} \mathrm{experiment,} \mathrm{our} \mathrm{only} \mathrm{mass} \mathrm{flow} \mathrm{meter} \mathrm{had} \mathrm{an} \mathrm{accuracy}$ of $0.15 \mathrm{std} \mathrm{l} / \mathrm{min}$. Since then, we have obtained a second mass flow meter for measuring flow rates between 0 and 1 std l/min with an accuracy of $0.015 \mathrm{std}$ l/min). Using the limewood diffuser, bubbles with a slip velocity of approximately $4 \mathrm{~cm} / \mathrm{s}$ (diameter less than $1 \mathrm{~mm}$ ) were created. Because 

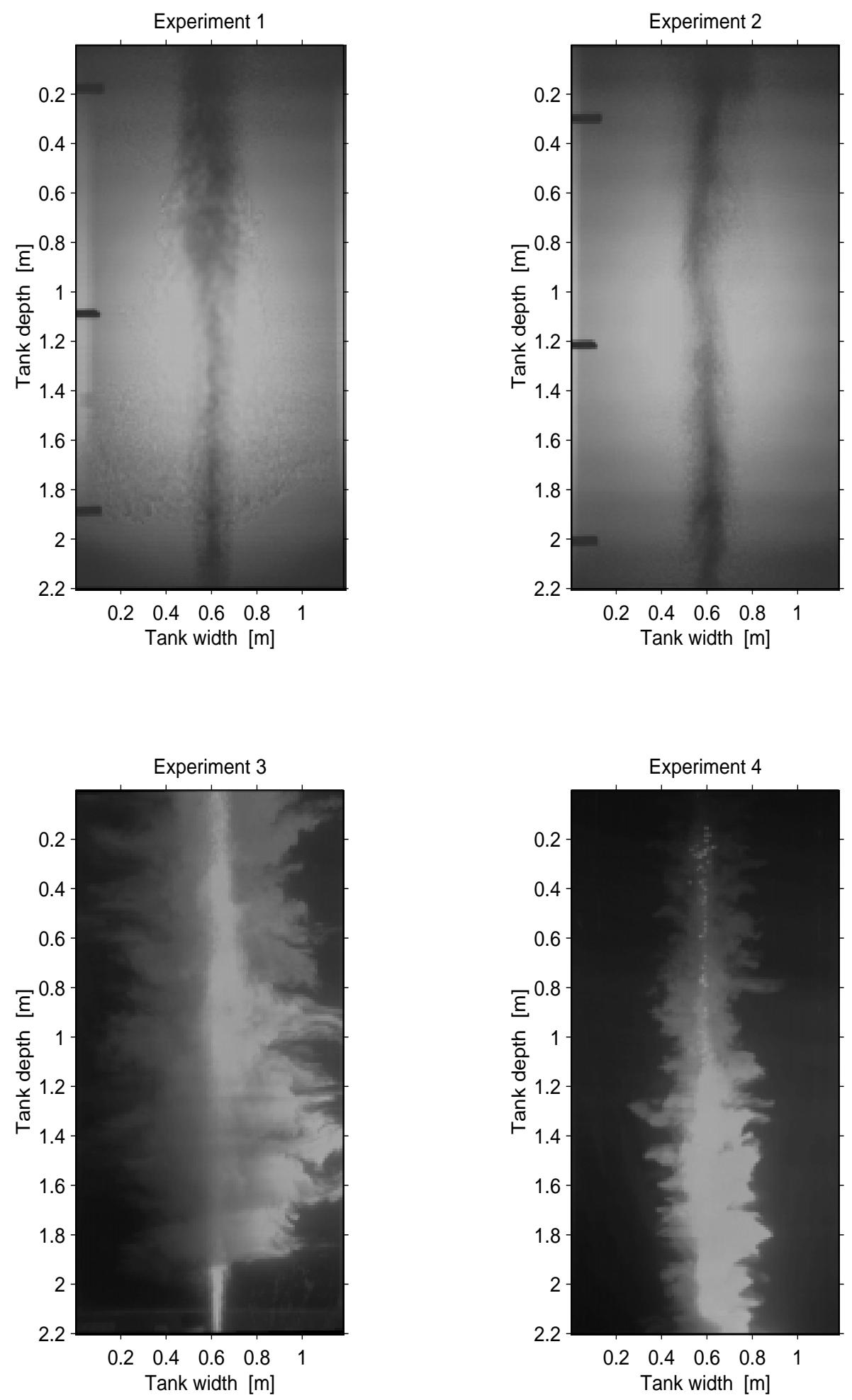

Figure 6: Images captured during Experiments 1-4. 
these bubbles were so small, they peeled with the first peel and the bubble core became spread out over an area about $30 \mathrm{~cm}$ in diameter (the first peel occurred $45 \mathrm{~cm}$ above the diffuser). The plume that developed above the first peel had a weak inner core, thus as subsequent peels started their downward motion, the peeled water would run into the upward moving plume, deflecting it, and sometimes causing additional, unsteady peels. The ultimate height of rise between peels was approximately constant, but peeling events were highly unsteady and dependent on peels tumbling from above. Because peels occurring at one level were able to fall down and interrupt peels at lower levels, it is assumed that only a portion of the entrained water was detrained at each peel. That is, dense water from the bottom is rising through two or more peels before it is ejected from the plume and is then able to fall down a distance greater than one peel before it intrudes.

\subsection{Experiment 3}

This was the first LIF experiment and was also our first observation of a Type 3 plume. The dye injected at the base of the plume easily reached the surface of the tank during the experiment, indicating again that only a fraction of the plume water was peeling at each peeling event. Because Type 3 plumes are described as continuously peeling, there was no way to see discrete points where the downward flowing annular plume was originating. The plume was created with the same airflow rate as Experiment 2, hoping that the slightly larger bubbles would remain coherent through the peels, creating steady Type 2 without bubble peeling. The bubbles did remain coherent; however, the higher slip velocity of the bubbles moved the plume to the Type 3 region. This experiment confirmed the Type 3 behavior region for larger values of $P_{N}$.

\subsection{Experiment 4}

This was the first experiment conducted with oil. The oil was injected at a flow rate of $0.25 \mathrm{std} \mathrm{l} / \mathrm{min}$ and produced droplets with diameters of about 1 to $2 \mathrm{~cm}$, having a slip velocity of $10 \mathrm{~cm} / \mathrm{s}$. Qualitatively, this plume looked exactly like that in Experiment 3, except that is took longer for the plume to grow because the oil was moving slower. Hence, this experiment enlarged the region of Type 3 plumes in Figure 5. Like experiment 3, the large droplets were not affected by the peeling episodes.

\subsection{Experiment 5}

Step stratification was used in this experiment to force a double-peeling, Type 2 plume. A bottom layer of dense brine was overlain by equal thicknesses of lighter saltwater and then fresh 
water. In this experiment we were also interested in seeing how the bubbles reform a plume after peeling with the plume fluid, so the limewood diffuser was selected with a low air-flow rate of $0.35 \mathrm{std} \mathrm{l} / \mathrm{min}$. The bubbles rose through the first layer entraining water, and peeled at the first interface along with at least $80 \%$ of the entrained fluid. After spreading out approximately to the plunge-point of the detraining fluid, the bubbles rose to reform a plume in the second layer, yielding a hyperbolic plume profile similar to smoke rising from a large brush fire. The bubbles were able to entrain some fluid and, therefore, peeled again at the second interface. A similar plume was reformed in the third layer. Hence, by this experiment, it is clear that the peeled bubbles continue to form plumes, but that their startup conditions are similar to a wide, diffuse source.

\section{Experimental Analysis}

As described in Section 3, there are two parameters that have been used to classify plume behavior and guide design: $P_{N}$ and $M_{H}$. The dependence of each of these parameters on the absolute pressure head at the diffuser orifice, $H$, works well in the case of reservoir destratification where the plume extends over the whole depth. However, for the deep ocean $\mathrm{CO}_{2}$ plume, the plume type should not be affected by changing the diffuser elevation, provided that all other variables remain constant. As a result, we seek a parameterization that is independent of $H$.

The simplest way to approach the derivation of $P_{N}$ and $M_{H}$ is through dimensional analysis. Starting with a single-phase plume in linear stratification, the important parameters are the buoyancy flux, $B$, and the stratification frequency, $N$. The dependent variable we would like to predict is the intrusion height, also known as the trap height, $h_{T}$. Arranging $B$ and $N$ to give dimensions of length and normalizing $h_{T}$, we define the first important non-dimensional group, $\pi_{1}$, as

$$
\pi_{1}=\left(\frac{N^{3} h_{T}^{4}}{B}\right)^{1 / 4}
$$

Since $P_{N}$ depends on $H$ instead of $h_{T}$, we obtain the following relationship between $\pi_{1}$ and $P_{N}$

$$
P_{N}=\left(\frac{H}{h_{T}} \pi_{1}\right)^{4}
$$

Through experiments (see, e.g. Reingold 1994, Fischer et al. 1979, and Turner 1986) the singlephase plume relationship

$$
\pi_{1}=3.8
$$

has been calibrated. This relationship has been verified from laboratory scales up to the scales of 
forest fires and volcanic eruptions.

Next, the simplest kind of two-phase plume is considered. A sediment plume, where particle expansion is negligible, introduces two-phase plume physics without the complication of pressure effects. Several sediment characteristics are important, including: size, density, shape, cohesion, etc. The terminal fall velocity of the sediment, or slip velocity, $u_{s}$, is itself a function of these parameters; hence, it is assumed that the slip velocity incorporates the important characteristics for describing the simple two-phase plume. Thus, the important parameters are $B, N$, and $u_{s}$. A second, independent non-dimensional group, $\pi_{2}$, is

$$
\pi_{2}=\frac{(B N)^{1 / 4}}{u_{s}}
$$

and $\pi_{1}$ should depend on $\pi_{2}$ for predicting the trap height. Using the sediment data in Reingold (1994), we calibrated the relationship

$$
\pi_{1}=\frac{-0.03}{\pi_{2}}+2.7
$$

This relationship may not be valid for large values of $\pi_{2}$ (very small slip velocity) since we would expect $\pi_{1}=3.8$ to be the limiting value, not $\pi_{1}=2.7$. Since we lack data in the range of very small $u_{s}$, this question remains open. For the wide range of slip velocities expected in the laboratory and the field experiment, however, this linear relationship has been validated (See Figure 7 discussed below).

Finally, we can consider the pressure effects resulting in bubble expansion. For ideal gas behavior, the important parameter would be $H$. Hence, the complete set of parameters for the expanding bubble plume in a stratified ambient would be $B, N, u_{s}$, and $H$. The only other independent dimensional group, $\pi_{3}$, is

$$
\pi_{3}=\frac{h_{T}}{H}
$$

Combining the three independent groups $\pi_{1}, \pi_{2}$, and $\pi_{3}$, we find an expression for $M_{H}$ given as

$$
M_{H}=\frac{\pi_{2}^{3} \pi_{3}}{4 \pi \alpha^{2} \pi_{1}}
$$

Thus, since $M_{H}$ includes $\pi_{3}$ it should be sensitive to the pressure effects of bubble expansion (note that $P_{N}$ also contains $\pi_{3}$ ). Since no laboratory data are available where expansion is significant, a third relationship for the trap height cannot be calibrated; however, it should have the form $\pi_{1}=f\left(\pi_{2}, \pi_{3}\right)$. 
McDougall originally analyzed this problem by non-dimensionalizing the governing equations for a bubble plume in stratification with expansion effects and noting that the non-dimensional solutions depended on $P_{N}$ and $M_{H}$. In his derivation of the buoyancy conservation equation, McDougall made the mistake of multiplying the expansion term by the plume velocity without adjusting the other terms in the equation, thus introducing an error (see Section 7 for a full discussion on the governing equations). The corrected equation following McDougall's assumptions should have the form:

$$
\frac{d}{d z}\left(\frac{U_{m} \pi b^{2} g^{\prime} \lambda^{2}}{1+\lambda^{2}}\right)=-\pi U_{m} b^{2} N^{2}+\frac{Q_{0} H_{a} g}{(H-z)^{2}}
$$

where we assume Gaussian profiles of plume velocity and mixture buoyancy, having centerline values of $U_{m}$ and $g^{\prime}$, respectively, $b$ is the characteristic width of the velocity profile, $\lambda$ is the turbulent Schmidt number representing the different rates of spread of the buoyancy and velocity profiles, $Q_{0}$ is the standard gas flow rate at atmospheric pressure, $H_{a}$ is the absolute atmospheric pressure head, and $z$ is the vertical coordinate, taken positive upward. To derive the correct relationships for a deep-ocean plume, we introduce the following non-dimensionalization:

$$
\begin{aligned}
z & =l X \\
b & =2 \alpha l B \\
U_{m} & =\left(1+\lambda^{2}\right) u_{s} V=U_{B} V \\
g^{\prime} & =\frac{U_{B}^{2}}{\lambda^{2} l} G
\end{aligned}
$$

where the capital letters represent the corresponding non-dimensional variables and $l$ is a characteristic length scale. If we let $l$ be the dimensional group $H / P_{N}^{1 / 4}$, then Equation 10 in non-dimensional form becomes

$$
\frac{d}{d X}\left(\frac{V B^{2} G}{1+\lambda^{2}}\right)=\pi_{2}^{2} V B+M_{H} \frac{1}{\left(1+\frac{X}{P_{N}}\right)^{2}}
$$

which can give insight into the effects described by the different non-dimensional groups. First, $\pi_{2}$ multiplies the stratification term. Naming this term $U_{N}$ because it is a normalized velocity, we have

$$
U_{N}=\frac{(B N)^{1 / 4}}{u_{s}}
$$

where the numerator is the characteristic plume fluid velocity and the denominator is just the slip velocity of the bubbles. Since $U_{N}$ multiplies the stratification term, it should describe the effects of the stratification on the overall plume characteristics. Since $P_{N}$ multiples just the length coordinate, it should represent the characteristic length scale in the problem, which is exactly what 
we assumed in the non-dimensionalization, validating our assumption. And since $M_{H}$ multiplies the whole second term, it should represent the effects of bubble expansion. The more general two-phase plume equations, as in Section 7, were also non-dimensionalized and gave similar conclusions.

The question arises, if $M_{H}$ only multiplies the bubble exansion term, why does it correlate well with many qualities of plume behavior, even when bubble expansion is not important? To find the answer, $M_{H}$ can be rewritten using $P_{N}$ and $U_{N}$ in the form

$$
M_{H}=\frac{U_{N}^{3}}{4 \pi \alpha P_{N}^{1 / 4}}
$$

thus, $M_{H}$ itself is not an independent parameter describing the plume. To see which of the two parameters, $U_{N}$ or $P_{N}, M_{H}$ is more dependent on, consider the laboratory scales used in the historical analysis. As was shown above, $P_{N}^{1 / 4}$ is proportional to the intrusion height, or the intrusion spacing (assuming uniform spacing). In laboratory settings the number of intrusions is generally between one and three; the $M_{H}$ parameter would behave approximately like $U_{N}$ times a constant spacing of intrusions. Hence, $M_{H}$ has been used to describe phenomena that are best described by $U_{N}$, and no complications have arisen since the value of $P_{N}^{1 / 4}$ has not varied over a wide enough range. Our analysis suggests, therefore, that the parameter $U_{N}$ should be used in place of $M_{H}$ to quantitatively describe plume behavior and that this assumption's significance should increase with increasing $P_{N}$. Additionally, the effects of bubble expansion would be addressed in an equation of the form $f\left(U_{N}, P_{N}\right)$.

To show the utility of our substitution of $U_{N}$ for $M_{H}$, two data sets were analyzed. Reingold (1994) investigated the dependence of the rise height of the first peel on slip velocity using sediment particles in a $70 \mathrm{~cm}$ deep, linearly-stratified tank. Figure 7 shows her data plotted using the new definition of $M_{H}$ along the x-axis. The data collapse to the straight line given in Equation 7 . The Asaeda and Imberger (1993) data were also re-evaluated. Figure 8 shows the same data as Figure 5 using $U_{N}$ instead of $M_{H}$. There is some ambiguity in the data for slip velocity reported in Asaeda and Imberger (1993); thus, the two Type 3 plumes that appear to fall in the Type 2 region of Figure 8 may not be reliable datapoints. The important feature to see is that the experiments lying on the transition from Type 2 to Type 3 have also collapsed to a straight line; hence the plume type can be taken as independent of the number of peels $\left(P_{N}\right)$, and additional sensitivity to other parameters, such as bubble characteristics, can be considered in a single plot.

Finally, the criteria for bubbles peeling with the plume fluid can be investigated by comparing the different experiments. In two experiments having everything equal accept bubble size (Experiments 2 and 3), bubbles peeled in the first case and did not peel in the second case. The important 


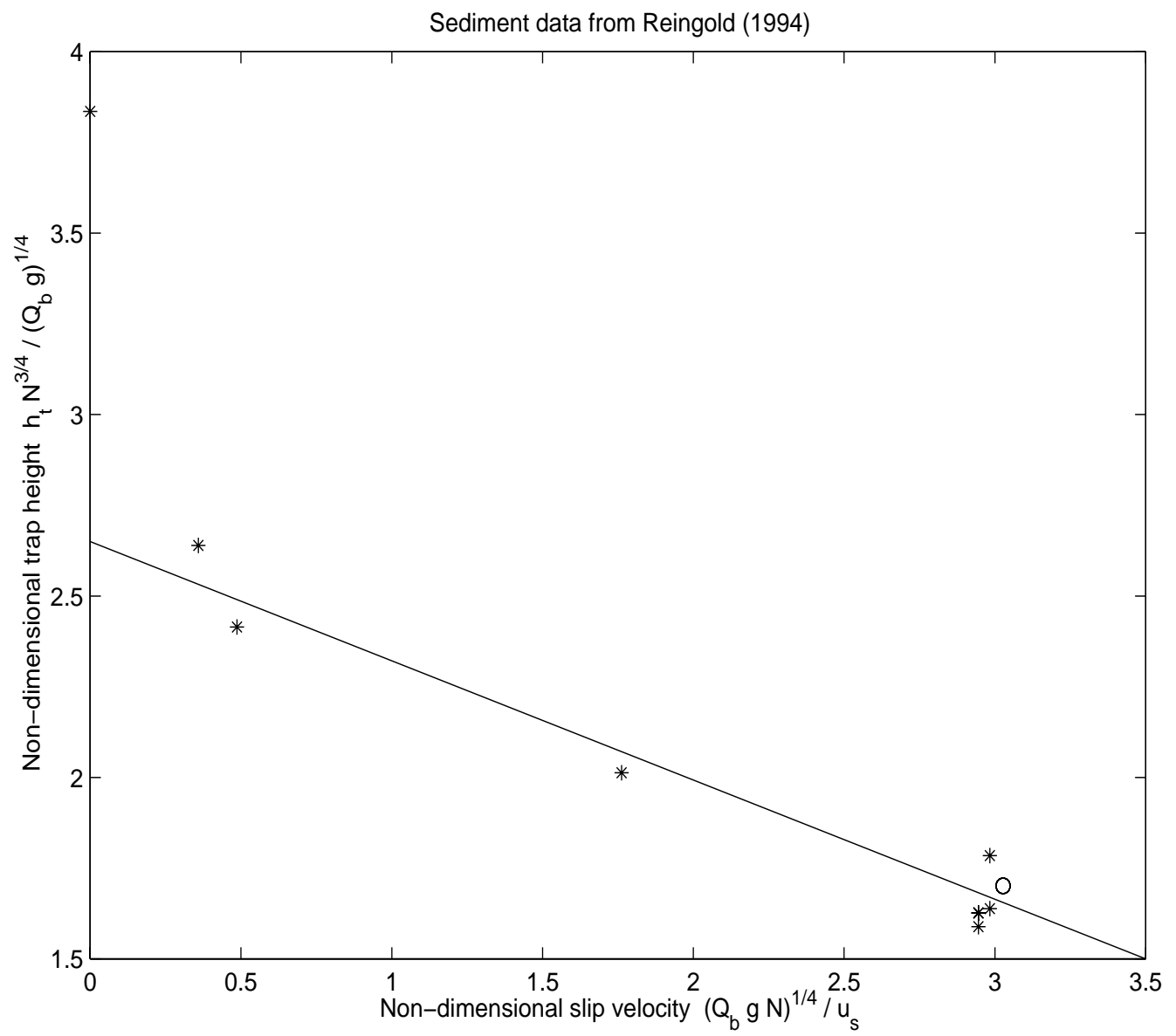

Figure 7: Non-dimensional trap height versus non-dimensional slip velocity for the Reingold (1994) sediment data. 


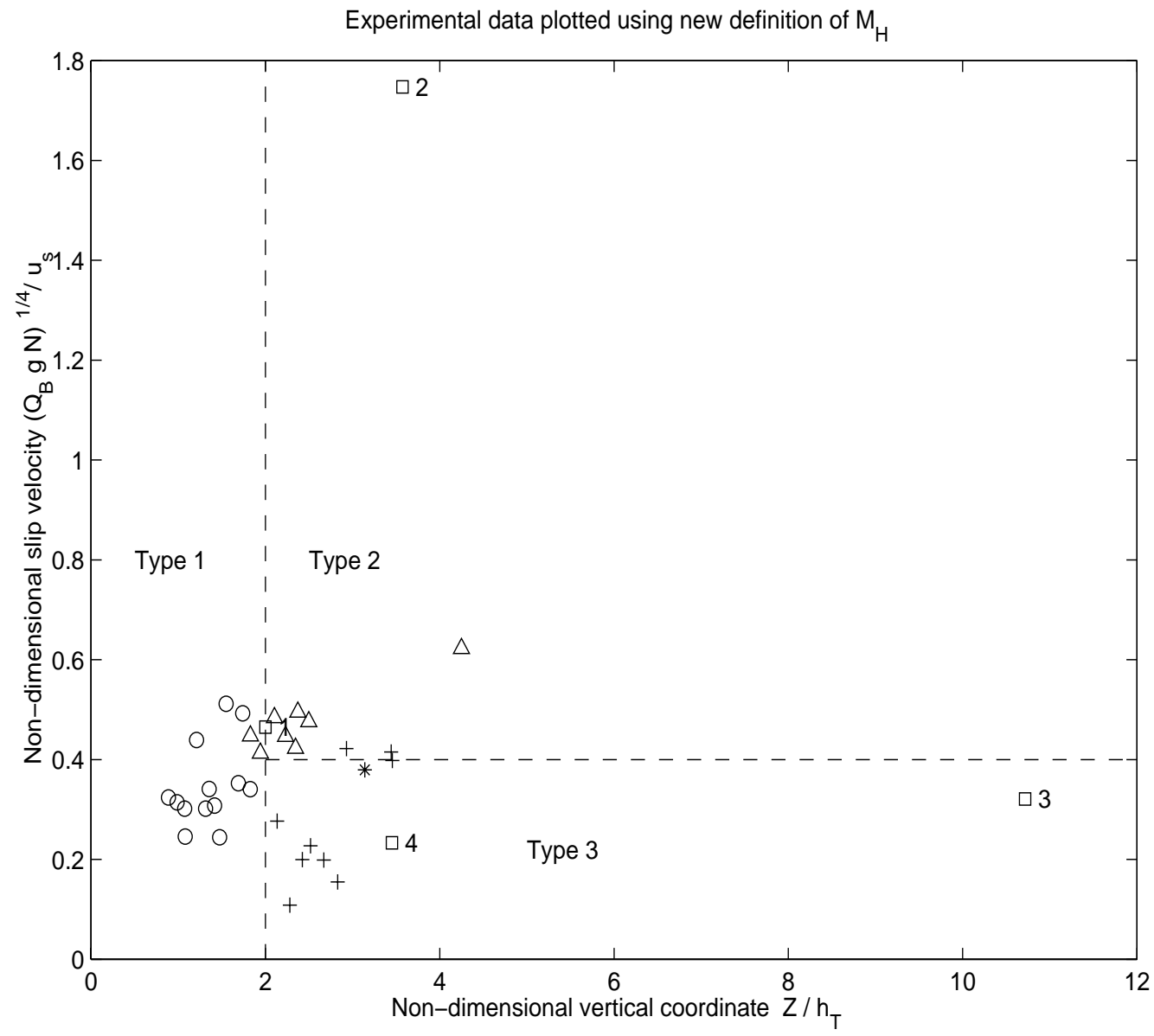

Figure 8: Asaeda and Imberger (1993) plot modified using the new definition of $M_{H}$. 


\begin{tabular}{|l|l|r|}
\hline Experiment & Bubbles & Threshold \\
\hline \hline 2 & Confined & 0.4 \\
\hline 3 & Peeled & 1.6 \\
\hline 4 & Confined & 0.3 \\
\hline $\mathrm{CO}_{2}$ & Unknown & 0.7 \\
\hline
\end{tabular}

Table 2: Peeling thresholds for bubbles that are confined to the inner core and move through a peel unaffected by the peeling fluid and for passive bubbles that are spread out by ejected fluid at a peeling episode. The final table entry is for a typical $\mathrm{CO}_{2}$ injection of $1 \mathrm{~kg} / \mathrm{s}$ at $1000 \mathrm{~m}$ depth.

variables for determining if bubbles peel are their size, slip velocity, mass, and the velocity scales in the plume fluid. Size and mass are relatable to slip velocity, so we are left, as before, with the ratio of the two velocity scales in the parameter $U_{N}$. Table 2 summarizes three of the Experiments and calculates values for a typical $\mathrm{CO}_{2}$ plume with $1 \mathrm{~kg} / \mathrm{s}$ release flux of $1 \mathrm{~cm}$ diameter bubbles at a depth of $1000 \mathrm{~m}$ using an ocean density profile taken near Hawaii. Based on these results, the $\mathrm{CO}_{2}$ plume lies between the values for bubbles that peel and bubbles that do not. Hence, there is potential that the $\mathrm{CO}_{2}$ bubbles could peel; therefore, studying the effects of bubble peeling is important.

\section{$7 \quad$ Numerical Analysis}

Work has continued on development of a numerical model of a bubble plume in a stratified environment. The current effort represents a blending of aspects of the Liro (1991) single plume model and the Asaeda and Imberger (1993) double plume model. Specifically, the ability of the Liro model to account for mass transfer from the bubbles to the ambient fluid is combined with the Asaeda and Imberger double plume model. This dissolution of mass can affect the density of the water in the plume, complicating plume structure.

Like its predecessors, this model integrates upward plume properties according to a set of governing equations, starting with a set of initial conditions. Like the Asaeda and Imberger model, this model also integrates outer, downward plume properties from a peel location. As the inner and outer plumes interact with one another, the model must iterate along the area of coincidence until the plume properties converge. Its purpose is to predict plume properties of interest, particularly total plume height, and the location and size of intrusions into the ambient environment.

The Asaeda and Imberger model causes 100 percent of the plume volume flux to be shed at peeling events. One result of this peeling scheme is that the resulting outer plume must reach 
neutral buoyancy at a height above the release point, or the next-deeper peel location. In contrast, the current model allows peeling fractions of less than 100 percent, and allows for the increase of plume water density due to dissolution of bubble material. This scheme thus allows for the possibility that an outer plume formed from a peel at a certain depth may in fact overlap with outer peels formed at deeper depths, and potentially can descend past the depth of injection. As a result, the model must account for overlapping behavior.

The model has the following capabilities:

- Use of arbitrary stratification profiles

- Variable initial bubble size, mass flux

- Variable bubble dissolution rate, effect on water density

- Choice of peel criteria: zero buoyancy or momentum flux

\subsection{Governing Equations}

The current model is governed by the conservation of five quantities: aqueous volume flux, $V_{f}$, total momentum flux, $M_{f}$, aqueous mass flux, $P_{f}$, mass flux of the material comprising the droplets or bubbles, $C_{f}$, and mass flux of dissolved material, $D_{f}$. These quantities are defined for both the inner and outer plumes.

For the inner plume:

$$
\begin{gathered}
V_{f}=\pi a^{2}\left(1-\lambda_{1} C\right) u \\
M_{f} \approx \xi \pi a^{2}\left(1-\lambda_{1} C\right) \rho_{i} u^{2} \\
P_{f}=\pi a^{2}\left(1-\lambda_{1} C\right) \rho_{i}^{\prime} u \\
D_{f}=\pi a^{2}\left(1-\lambda_{1} C\right) C_{d i} u \\
C_{f}=\pi a^{2} \lambda_{1} C \rho\left(u+u_{b}\right)
\end{gathered}
$$


a Inner plume radius in $\mathrm{m}$

$u \quad$ Inner plume velocity in $\mathrm{m} / \mathrm{s}$

$\rho_{i} \quad$ Density of water, inner plume in $\mathrm{kg} / \mathrm{m}^{3}$

$C_{d i}$ Concentration of dissolved matter in $\mathrm{kg} / \mathrm{m}^{3}$

$\rho_{i}^{\prime} \quad$ Density of water excluding dissolved matter, $\rho i-C_{d i}$

$C \quad$ Volume fraction of bubble core occupied by bubbles.

$\lambda_{1} \quad$ Spreading ratio of bubble core to inner plume radius.

$\rho \quad$ Density of bubble material in $\mathrm{kg} / \mathrm{m}^{3}$

$\xi \quad$ Turbulent momentum factor

For the outer plume:

$$
\begin{gathered}
V_{f}=\pi\left(b^{2}-a^{2}\right) v \\
M_{f}=\xi \pi\left(b^{2}-a^{2}\right) \rho_{o} v^{2} \\
P_{f}=\pi\left(b^{2}-a^{2}\right) \rho_{o}^{\prime} v \\
D_{f}=\pi\left(b^{2}-a^{2}\right) C_{d o} u \\
C_{f}=0
\end{gathered}
$$

$b \quad$ Outer plume radius in $\mathrm{m}$

$v \quad$ Outer plume velocity in $\mathrm{m} / \mathrm{s}$

$\rho_{o} \quad$ Density of water in outer plume in $\mathrm{kg} / \mathrm{m}^{3}$

$C_{d o} \quad$ Concentration of dissolved matter in $\mathrm{kg} / \mathrm{m}^{3}$

$\rho_{o}^{\prime} \quad$ Density of water excluding dissolved matter, $\rho i-C_{d i}$

All fluxes and velocities are defined positive in the upward direction. The inner plume fluxes and $u$ are positive, while the corresponding values for the downward-flowing outer plume are negative.

The values of these quantities are governed by the following differential equations:

For the inner plume:

$$
\begin{gathered}
V_{f \beta}=2 \pi a \beta(u-v) \\
V_{f \gamma}=2 \pi a \gamma v \\
\frac{d}{d x} V_{f}=V_{f \beta}+V_{f \gamma}+\bar{V}_{C O_{2}} \frac{d}{d x} C_{f}
\end{gathered}
$$




$$
\begin{gathered}
\frac{d}{d x} M_{f}=\pi a^{2} g\left(\lambda_{1}^{2} C\left(\rho_{a}-\rho\right)+\left(1-\lambda_{1}^{2} C\right)\left(\rho_{a}-\rho_{i}\right)\right)+V_{f \beta} \rho_{o} v+V_{f \gamma} \rho_{i} u \\
\frac{d}{d x} P_{f}=V_{f \beta} \rho_{o}^{\prime}+V_{\gamma} \rho_{i}^{\prime} \\
\frac{d}{d x} D_{f}=\frac{d}{d x} C_{f}+V_{f \beta} C_{d o}+V_{\gamma} C_{d i} \\
\frac{d}{d x} C_{f}=\frac{4 \pi r^{2} N_{b} K C_{s}}{u+u_{b}}
\end{gathered}
$$

$x \quad$ Positive upward

$\beta, \gamma \quad$ Entrainment coefficients

$g \quad$ Gravitational acceleration in $\mathrm{m} / \mathrm{s}^{2}$

$\rho_{a} \quad$ Ambient water density

$\bar{V}_{\mathrm{CO}_{2}} \quad$ Specific volume of $\mathrm{CO}_{2}$ in $\mathrm{m}^{3} / \mathrm{kg}$

$N_{b} \quad$ Bubble flux

$r \quad$ Bubble radius in $\mathrm{m}$

$K \quad$ Mass transfer coefficient in $\mathrm{m} / \mathrm{s}$

For the outer Plume:

$$
\begin{gathered}
V_{f \alpha}=2 \pi b \alpha v \\
V_{f \beta}=2 \pi a \beta(u-v) \\
V_{f \gamma}=2 \pi a \gamma v \\
\frac{d}{d z} V_{f}=V_{f \alpha}+V_{f \beta}+V_{f \gamma} \\
\frac{d}{d z} M_{f}=\pi\left(b^{2}-a^{2}\right) g\left(\left(1-\lambda_{1}^{2} C\right)\left(\rho_{a}-\rho_{o}\right)-V_{f \beta} \rho_{o} v-V_{\gamma} \rho i u\right. \\
\frac{d}{d z} P_{f}=V_{f \beta} \rho_{o}^{\prime}+V_{\gamma} \rho_{i}^{\prime} \\
\frac{d}{d z} D_{f}=V_{f \beta} C_{d o}+V_{\gamma} C_{d i} \\
\frac{d}{d z} C_{f}=0
\end{gathered}
$$




\begin{tabular}{|l|c|c|c|}
\hline Case & 1 & 2 & 3 \\
\hline \hline Mass Transfer Rate & Full & $1 / 10$ Full & Full \\
\hline $\bar{V}_{\mathrm{CO}_{2}}$ & $31 \mathrm{~cm}^{3} / \mathrm{mol}$ & $31 \mathrm{~cm}^{3} / \mathrm{mol}$ & $0 \mathrm{~cm}^{3} / \mathrm{mol}$ \\
\hline
\end{tabular}

Table 3: Description of numerical case studies.

$\begin{array}{ll}z & \text { Positive downward }=-x \\ \alpha, \beta, \gamma & \text { Entrainment coefficients } \\ g & \text { Gravitational acceleration in } \mathrm{m} / \mathrm{s}^{2} \\ \rho_{a} & \text { Ambient water density }\end{array}$

\section{$7.2 \quad$ Status}

The model is currently being tested for robustness. The current peel scheme results in sharp gradients in plume properties at peel locations. As outer plumes can overlap underlying peel locations in this model, it is necessary in some cases to integrate across these gradients, introducing potential stability issues. Further, in cases where the outer plume achieves high velocities relative to the inner plume, due to negative buoyancy induced by bubble dissolution, the entrainment assumptions invoked by this model may not be applicable, and are under review.

The next step for model development is to calibrate this model to experimental results. The primary applicable parameters are the three entrainment coefficients, and the peeling parameters (location and percent of volume flux shed). Once calibrated, the model can then be applied to field situations, including those in which bubble dissolution is significant.

\subsection{Results}

The following results are preliminary, and are meant only to illustrate sensitivity to some parameters. As the model is not yet calibrated, these results may not be accurate.

Three cases are presented here. In each case, $1 \mathrm{~kg} / \mathrm{s}$ of $\mathrm{CO}_{2}$ is released at a depth of $1000 \mathrm{~m}$, with a generic oceanic stratification profile. In one case, the mass transfer rate from the bubbles to the plume water is greatly reduced from the base ("full") value. This is of interest because there is a potential for clathrate hydrate formation on the surface of the bubbles. The other parameter we varied among cases is the specific volume of $\mathrm{CO}_{2}$, in order to understand the model sensitivity to this parameter. For each case, the resultant plume was modeled as both a single plume with discrete peels lost to the environment (similar to Liro), and as a double plume, akin to Asaeda and 

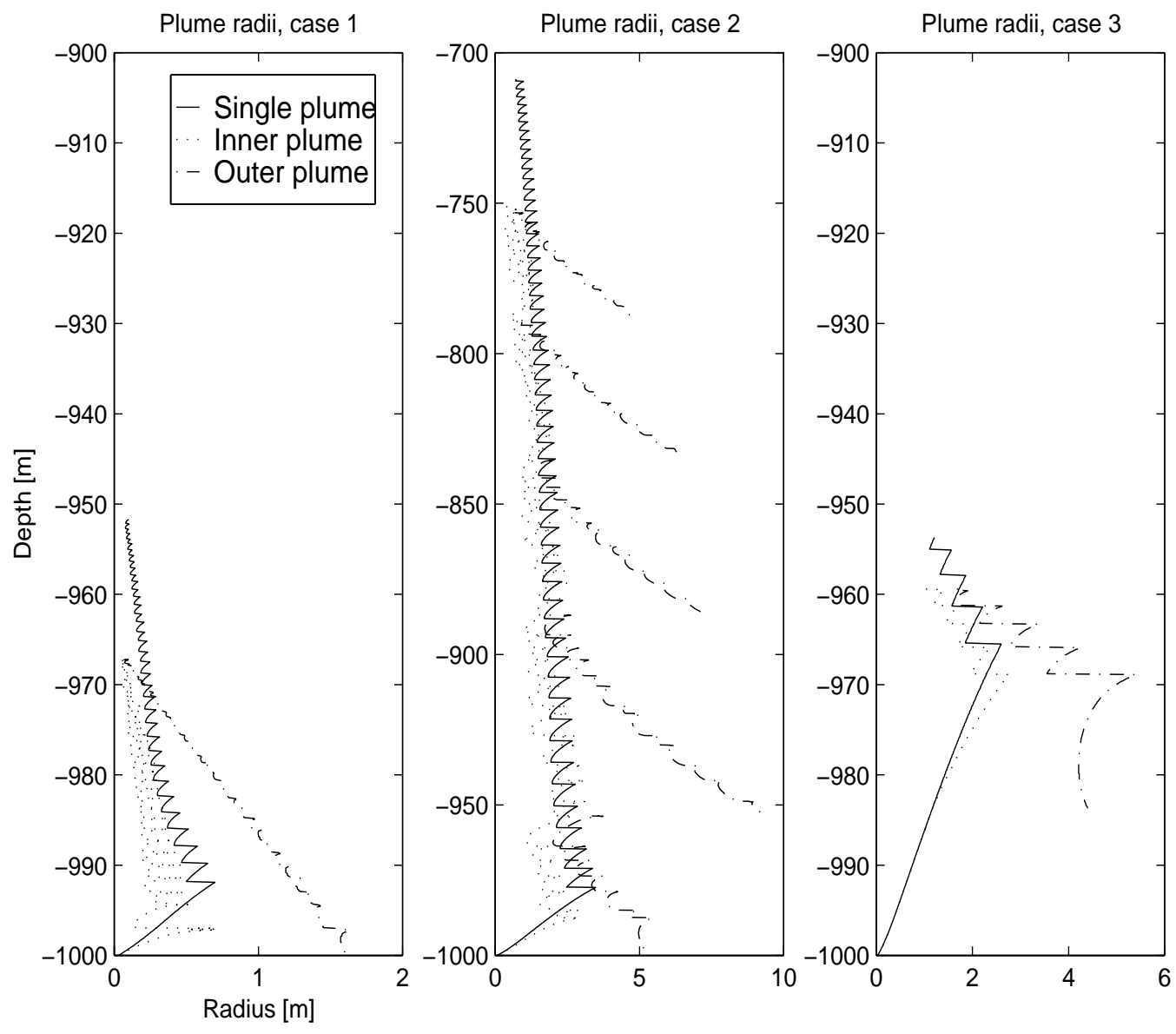

Figure 9: Computer model $\mathrm{CO}_{2}$ plume profiles for Cases 1-3.

Imberger, for a total of six model runs. The resulting plume profiles are shown in Figure 9, and the corresponding dissolved $\mathrm{CO}_{2}$ concentrations are shown in Figure 10. The axes for the plot of each case vary in order to satisfactorily represent the structure of each plume.

The resulting plume profiles are qualitatively different from one another. Case 1, with high mass transfer and the effect of $\mathrm{CO}_{2}$ dissolution on water density, results in a short, compact plume, characterized by high levels of dissolved $\mathrm{CO}_{2}$, and, in the double plume case, an outer plume which descends below the point of injection. Case 2, with reduced mass transfer, produces a relatively tall plume with low $\mathrm{CO}_{2}$ concentrations. Several distinct outer plumes are predicted to form and intrude roughly 50 meters apart in the double plume case. Case 3, without the $\mathrm{CO}_{2}$ dissolution effect on density, results in a plume similar in height to Case 1, but with a greater radius. In the double plume model, one distinct outer layer forms and intrudes at an intermediate depth. Table 4 summarizes the relative plume rise heights. The first two rows indicate height ratios relative to 

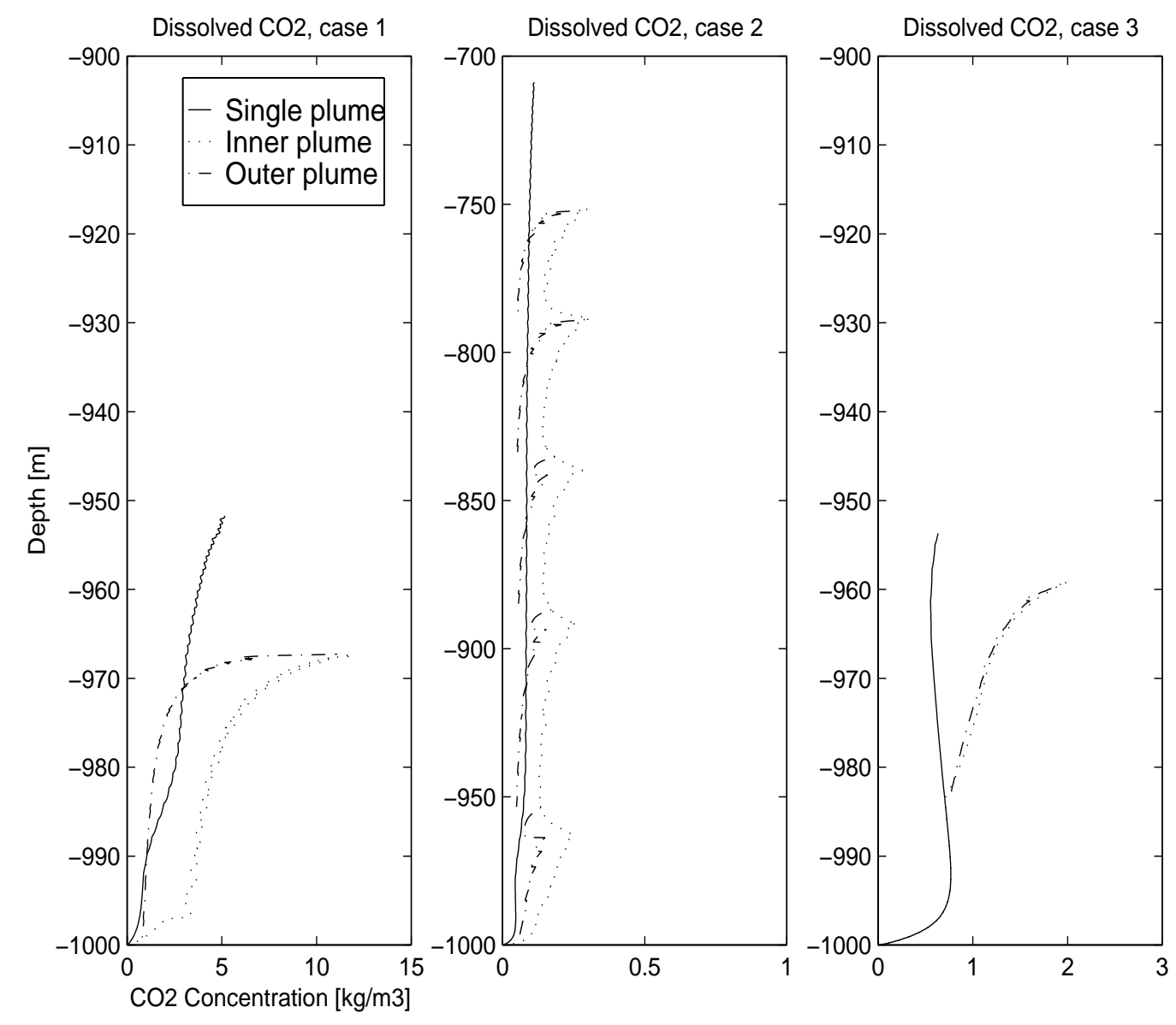

Figure 10: Computer model $\mathrm{CO}_{2}$ plume centerline dissolved $\mathrm{CO}_{2}$ concentrations for Cases 1-3. 


\begin{tabular}{|l|c|c|c|}
\hline Case & 1 & 2 & 3 \\
\hline \hline Single Plume Height & 1.0 & 6.03 & 0.96 \\
\hline Double Plume Height & 1.0 & 7.63 & 1.27 \\
\hline Single to Double Plume & 0.68 & 0.86 & 0.90 \\
\hline
\end{tabular}

Table 4: Plume rise heights for Cases 1-3.

Case 1, while the third row represents the plume height predicted by the double plume model relative to the single plume model prediction for each respective case. One interesting result is that the dissolved $\mathrm{CO}_{2}$ concentrations are lower for the single plume models with respect to the corresponding double plume models. This result is due to the fact that the single plume model assumes that the dissolved $\mathrm{CO}_{2}$ shed at peeling events is lost to the ambient environment; for the double plume model, dissolved $\mathrm{CO}_{2}$ only leaves the plume where the outer plumes intrude at neutral density.

The dissolved CO2 enters the ambient environment primarily at the location, or locations, where the outer, descending plume(s) reach neutral buoyancy and begin to spread laterally. For Cases 1 and 3, with rapid CO2 dissolution, the initial CO2 concentrations at the points of intrusion are about $0.75 \mathrm{~kg} / \mathrm{m} 3$, or about $17 \mathrm{mmol} / \mathrm{kg}$ seawater. Assuming an alkalinity of about $2.35 \mathrm{meq} / \mathrm{kg}$, this total CO2 concentration will result in a $\mathrm{pH}$ drop at equilibrium of 2.7 units, from 7.9 to 5.1 , at horizontal distances of about one meter from the discharge. For the case with slower mass transfer, Case 2, the resulting $\mathrm{pH}$ drop will be 1.5 units, at horizontal distances of order $5 \mathrm{~m}$ from the discharge. These values represent the maximum $\mathrm{pH}$ drop outside the plume core.

These estimates must be accompanied by some disclaimers. First, the latter figure is quite approximate, as the $\mathrm{CO} 2$ concentrations at the points of intrusion for Case 2 are comparable (0.05 $\mathrm{kg} / \mathrm{m} 3$ ) to ambient concentrations; the $\mathrm{pH}$ is quite sensitive to total $\mathrm{CO} 2$ in this region. Second, the kinetics of the dissociation of carbonic acid are rather slow, so the actual $\mathrm{pH}$ deficits near the plume may be lower than the preceding estimates. Third, it must be remembered that these results are quite preliminary; the model has not yet been verified. Finally, these results pertain to conditions without a current; an ambient current will increase dilution.

\subsection{Comments}

We must stress that these results are preliminary, and are presented only to illustrate the capabilities of the model. It is clear that the double plume modeling strategy produces predictions concerning the plume structure and the fate of peeled water that are significantly different from the 
single plume case, illustrating the need for development of the more complex double plume model. The next major objective of the modeling effort is to verify the double plume model and calibrate it by comparison with laboratory results.

\section{Conclusions}

Experimental and numerical studies have yielded a better understanding of the behavior of proposed deep ocean $\mathrm{CO}_{2}$ droplet plumes. The important observations include the following:

- The amount of fluid that peels at a detrainment event is not a fixed quantity, but rather depends on the droplet characteristics (bubble slip velocity) and the strength of the stratification.

- Dye injected at the base of a plume can rise through many peels for plumes in the Type 3 classification.

- Although the plume type classification has been verified for a wide range of parameter values, plumes with small droplets that may spread out at a peel deviate in behavior from the three modes of plumes identified by Asaeda and Imberger (1993).

- Bubble slip velocity and initial buoyancy flux are the important parameters for determining the threshold at which droplets are affected by peeling events for a given strength of stratification.

- Oil droplets are an acceptable model for $\mathrm{CO}_{2}$ droplets in a laboratory setting.

- A double plume model in the style of Asaeda and Imberger (1993) can be applied to the $\mathrm{CO}_{2}$ plume and remains stable when peels may run into each other as they descend to a level of neutral buoyancy.

- For a double plume in stagnant water, a significant amount of peeled fluid may be re-entrained, increasing the concentration of dissolved $\mathrm{CO}_{2}$ in the droplet plume.

Our experimental facility and computer models have been developed with flexibility in mind so that as quantitative results are attached to these observations, they can be easily included in the analysis of $\mathrm{CO}_{2}$ plumes.

As the computer models are calibrated to the experimental data, better predictions of the fate of injected $\mathrm{CO}_{2}$ in the deep ocean will aid in planning for the upcoming international field experiment and are expected to provide encouraging answers toward the feasibility of ocean $\mathrm{CO}_{2}$ disposal. The 
unique insights on two-phase plumes provided by the $\mathrm{CO}_{2}$ release also contribute a unique breadth of knowledge to the growing scientific understanding of these flows. Thus, these studies provide a framework of understanding for the onging work in this field.

\section{References}

[1] E. E. Adams. Experimental studies of droplet plumes as applied to ocean $\mathrm{CO}_{2}$ disposal. Technical report, Grant Proposal to the DOE, Massachusetts Institute of Technology, Cambridge, Massachusetts, September 1996.

[2] E. E. Adams, D. S. Golomb, and H. J. Herzog. Ocean disposal of $\mathrm{CO}_{2}$ at intermediate depths. Energy Conservation Management, 36(6-9):447-452, 1994.

[3] E. E. Adams and H. J. Herzog. Environmental impacts of ocean disposal of $\mathrm{CO}_{2}$. Technical Report MIT-EL 96-003, Energy Laboratory, Massachusetts Institute of Technology, 1996.

[4] E. Eric Adams, Jennifer A. Caulfield, Howard J. Herzog, and David I. Auerbach. Impacts of reduced $\mathrm{pH}$ from ocean $\mathrm{CO}_{2}$ disposal: Sensitivity of zooplankton mortality to model parameters. Waste Management, pages 375-380, 1997.

[5] I. Akhatov, U. Parlitz, and W. Lauterborn. Towards a theory of self-organization phenomena in bubble-liquid mixtures. Physical Review E, 54(5):4990-5003, 1996.

[6] G. Alendal, H. Drange, and F. Thorkildsen. Two-phase modeling of $\mathrm{CO}_{2}$ droplet plumes. Technical Report 153, Nansen Environmental and Remote Sensing Center, 1998.

[7] S. L. Anderson and E. K. Longmire. Interpretation of PIV autocorrelation mesurements [sic.] in complex particle-laden flows. Experiments in Fluids, 20:314-317, 1996.

[8] Takashi Asaeda and Jörg Imberger. Structure of bubble plumes in linearly stratified environments. Journal of Fluid Mechanics, 249:35-57, 1993.

[9] David I. Auerbach, Jennifer A. Caulfield, E. Eric Adams, and Howard J. Herzog. Impacts of ocean $\mathrm{CO}_{2}$ disposal on marine life: I. A toxicological assessment integrating constantconcentration laboratory assay data with variable concentration field exposure. Environmental Modeling and Assessment 2, pages 333-343, 1997.

[10] R. E. Baddour. Thermal-saline bubble plumes. In P. A. Davies and M. J. Valente Neves, editors, Recent Research Advances in the Fluid Mechanics of Turbulent Jets and Plumes, pages 117-129, The Netherlands, 1994. Kluwer Academic Publishers. 
[11] W. D. Baines and A. M. Leitch. Destruction of stratification by bubble plumes. Journal of Hydraulic Engineering, 118(4):559-577, 1992.

[12] G. K. Batchelor. Heat convection and buoyancy effects in fluids. Quarterly Journal of The Royal Meteorological Society, 80:339-358, 1954.

[13] Jens Beyersdorf. Verhalten von Luftblasen und Sedimenten in Blasensäulen in abhängigkeit vom Saltzgehalt im Wasser. Mitteilungen, Heft 79, Franzius-Institut f. Wasserbau u. Küsteningenieurwesen, Universität Hannover, 1997.

[14] Marco A. S. C. Castello-Branco and Klaus Schwerdtfeger. Characteristics of eccentric bubble plumes in liquids. Metallurgical and Materials Transactions B, 27B:231-239, 1996.

[15] Jennifer A. Caulfield, E. Eric Adams, David I. Auerbach, and Howard J. Herzog. Impacts of ocean $\mathrm{CO}_{2}$ disposal on marine life: II. Probabilistic plume exposure model used with a timevarying dose-response analysis. Environmental Modeling and Assessment 2, pages 345-353, 1997.

[16] Jennifer Ann Caulfield. Environmental impacts of carbon dioxide ocean disposal: Plume predictions and time dependent organism experience. Master's thesis, Massachusetts Institute of Technology, Department of Civil and Environmental Engineering, 1996.

[17] Klas Cederwall and John D. Ditmars. Analysis of air-bubble plumes. Technical Report KH-R24, W. M. Keck Laboratory of Hydraulics and Water Resources, Division of Engineering and Applied Science, California Institute of Technology, Pasadena, California, September 1970.

[18] Antonio Cenedese and Paolo Viotti. Lagrangian analysis of nonreactive pollutant dispersion in porous media by means of the particle image velocimetry technique. Water Resources Research, 32(8):2329-2343, 1996.

[19] F. B. Cheung and M. Epstein. Two-phase gas bubble-liquid boundary layer flow along vertical and inclined surfaces. Nuclear Engineering and Design, 99(1):93-100, 1987.

[20] John D. Ditmars and Klas Cederwall. Analysis of air-bubble plumes. In Proceedings of the Fourteenth Conference on Coastal Engineering, Copenhagen, Denmark, pages 2209-2226. American Society of Civil Engineers, June 1974.

[21] H. B. Fischer, E. G. List, R. C. Y Koh, J. Imberger, and N. H. Brooks. Mixing in Inland and Coastal Waters. Academic Press, San Diego, California, 1979. 
[22] L. H. J. Goossens. Reservoir Destratification with Bubble Columns. Delft University Press, Delft, The Netherlands, 1979.

[23] Imad A. Hannoun, Harindra J. S. Fernando, and E. John List. Turbulence structure near a sharp density interface. Journal of Fluid Mechanics, 189:189-209, 1988.

[24] J. Hartmann, J. Köhler, W. Stolz, and H. H. Flögel. Evaluation of instationary flow fields using crosscorrelation in image sequences. Experiments in Fluids, 20:210-217, 1996.

[25] J. W. Hoyt and R. H. J. Sellin. A turbulent dye streak technique. Experiments in Fluids, 20:38-41, 1995 .

[26] Christop Hugi. Modelluntersuchungen von Blasenstrahlen für die Seebelüftung. Ph.D. Thesis, Inst. f. Hydromechanik u. Wasserwirtschaft, ETH, Zürich, 1993.

[27] N. A. Hussain and B. S. Narang. Simplified analysis of air-bubble plumes in moderately stratified environments. Journal of Heat Transfer, 106:543-551, 1984.

[28] M. L. Jakobsen, W. J. Easson, C. A. Greated, and D. H. Glass. Particle image velocimetry: simultaneous two-phase flow measurements. Measurement Science and Technology, 7:12701280, 1996.

[29] Warren T. Jones. Air barriers as oil-spill containment devices. Society of Petroleum Engineers Journal, pages 126-142, April 1972.

[30] Helmut E. Kobus. Analysis of the flow induced by air-bubble systems. In Proceedings of the Eleventh Conference on Coastal Engineering, London, England, pages 1016-1031. American Society of Civil Engineers, September 1968.

[31] C. Gui L and W. Merzkirch. A method of tracking ensembles of particle images. Experiments in Fluids, 21:465-468, 1996.

[32] Magnus Larson and Lennart Jönsson. Modeling of mixing by turbulent jet in stably stratified fluid. Journal of Hydraulic Engineering, 121(12):853-862, 1995.

[33] A. M. Leitch and W. D. Baines. Liquid volume flux in a weak bubble plume. Journal of Fluid Mechanics, 205:77-98, 1989.

[34] Charles J. Lemckert and Jörg Imberger. Energetic bubble plumes in arbitrary stratification. Journal of Hydraulic Engineering, 119(6):680-703, 1993. 
[35] C. R. Liro, E. E. Adams, and H. J. Herzog. Modeling the release of $\mathrm{CO}_{2}$ in the deep ocean. Technical Report MIT-EL 91-002, Energy Laboratory, Massachusetts Institute of Technology, June 1991.

[36] C. R. Liro, E. E. Adams, and H. J. Herzog. Modeling the release of $\mathrm{CO}_{2}$ in the deep ocean. Energy Conservation Management, 33(5-8):667-674, 1992.

[37] Shiro Matsunashi and Yoichi Miyanaga. A field study on the characteristics of air bubble plume in a reservoir. Journal of Hydroscience and Hydraulic Engineering, 8(2):65-77, 1990.

[38] T. Maxworthy, C. Gnann, M Kürten, and F. Durst. Experiments on the rise of air bubbles in clean viscous liquids. Journal of Fluid Mechanics, 321:421-441, 1996.

[39] H. P. Mazumdar, N. Islam, and A. Chanda. A mathematical model for turbulent bubble plume. Physica Scripta, 53:575-581, 1996.

[40] Trevor J. McDougall. Bubble plumes in stratified environments. Journal of Fluid Mechanics, 85(4):655-672, 1978.

[41] Trevor J. McDougall. On the elimination of refractive-index variations in turbulent densitystratified liquid flows. Journal of Fluid Mechanics, 93(1):83-96, 1979.

[42] Wolfgang Merkirch. Flow Visualization. Academic Press, Orlando, Florida, second edition, 1987.

[43] J. H. Milgram. Mean flow in round bubble plumes. Journal of Fluid Mechanics, 133:345-376, 1983.

[44] B. R. Morton. Forced plumes. Journal of Fluid Mechanics, 5:151-163, 1959.

[45] B. R. Morton, Sir G. I. Taylor, and J. S. Turner. Turbulent gravitational convection from maintained and instantaneous sources. Proceedings of the Royal Society, A234:1-23, 1956.

[46] Tom R. Oakley, Eric Loth, and Ronald J. Adrian. Cenematic particle image velocimetry of high-Reynolds-number turbulent free shear layer. AIAA Journal, 34(2):299-308, February 1996.

[47] T. Osborn, D. M. Farmer, S. Vagle, S. A. Thorpe, and M. Cure. Measurements of bubble plumes and turbulence from a submarine. Atmosphere-Ocean, 30(3):419-440, 1992. 
[48] Panos N. Papanicolaou and E. John List. Investigations of round turbulent buoyant jets. Journal of Fluid Mechanics, 195:341-391, 1988.

[49] John C. Patterson and Jörg Imberger. Simulation of bubble plume destratification systems in reservoirs. Aquatic Sciences, 51(1):1 - 18, 1989.

[50] J. Reese, P. Jiang, and L.-S. Fan. Bubble characteristics in three-phase systems used for pulp and paper processing. Chemical Engineering Science, 51(10):2501-2510, 1996.

[51] Leah Sarah Reingold. An experimental comparison of bubble and sediment plumes in stratified environments. Master's thesis, Massachusetts Institute of Technology, Department of Civil and Environmental Engineering, 1994.

[52] S. Geoffrey Schladow. A design methodology for bubble plume destratification systems. In Lee and Cheung, editors, Environmental Hydraulics, Rotterdam, 1991. Balkema.

[53] S. Geoffrey Schladow. Observations of artificial destratification. In H. W. Shen, S. T. Su, and F. Wen, editors, Hydraulic Engineering. ASCE, 1993a.

[54] S. Goeffrey Schladow. Lake destratification by bubble-plume systems: Design methodology. Journal of Hydraulic Engineering, 119(3):350-368, 1993b.

[55] Jennifer Anne Sullivan. Effects of marsh grass on diffusivity. Master's thesis, Massachusetts Institute of Technology, Department of Civil and Environmental Engineering, 1996.

[56] T. Y. Sun and G. M. Faeth. Structure of turbulent bubbly jets-I. Methods and centerline properties. International Journal of Multiphase Flow, 12(1):99-114, January/February 1986.

[57] T. Y. Sun and G. M. Faeth. Structure of turbulent bubbly jets-II. Phase property profiles. International Journal of Multiphase Flow, 12(1):115-126, January/February 1986.

[58] K. H. Tacke, H. G. Schubert, D. J. Weber, and Klaus Schwerdtfeger. Characteristics of round vertical gas bubble jets. Metallurgical Transactions B, 16B(2):263-275, June 1985.

[59] Finn Thorkildsen, Guttorm Alendal, and Peter M. Haugan. Modelling of $\mathrm{CO}_{2}$ droplet plumes. Technical report, Nansen Environmental and Remote Sensing Center, Adv. Griegsvei 3A, N 5037 Solheimsviken, Norway, 1995.

[60] J. S. Turner. Turbulent entrainment: the development of the entrainment assumption, and its application to geophysical flows. Journal of Fluid Mechanics, 173:431-471, 1986. 
[61] J. Westerweel, A. A. Draad, J. G. Th. van der Hoeven, and J. van Oord. Measurement of fully-developed turbulent pipe flow with digital particle image velocimetry. Experiments in Fluids, 20:165-177, 1996.

[62] David L. Wilkinson. Two-dimensional bubble plumes. Journal of the Hydraulics Division, 105(HY2):139-154, 1979.

[63] Alfred Wüest, Norman H. Brooks, and Dieter M. Imboden. Bubble plume modeling for lake restoration. Water Resources Research, 28(12):3235-3250, 1992.

[64] M. Yoda and H. E. Fiedler. The round jet in a uniform counterflow: flow visualization and mean concentration measurements. Experiments in Fluids, 21:427-436, 1996.

[65] K. Zic, H. G. Stefan, and C. Ellis. Laboratory study of water destratification by a bubble plume. Journal of Hydraulic Research, 30(1):7-27, 1992. 